\title{
THE IMPACT OF GOVERNMENT FUNDING CUTS ON ETHNO- SPECIFIC SETTLEMENT SERVICES IN ONTARIO: THE CASE OF THE AFGHAN ASSOCIATION OF ONTARIO AND THE AFGHAN WOMEN'S ORGANIZATION
}

\author{
By: Alina Mohsini, B.A., Bennington College, 2010
}

\author{
A Major Research Paper \\ Presented to Ryerson University \\ In partial fulfillment of the requirements for the degree of \\ Master of Arts \\ In the Program of \\ Immigration and Settlement Studies
}

Toronto, Ontario, Canada, 2017

(C) Alina Mohsini, 2017 


\section{Author's Declaration for Electronic Submission of a Major Research Paper}

I hereby declare that I am the sole author of this major research paper. This is a true copy of the MRP, including any required final revisions.

I authorize Ryerson University to lend this paper to other institutions or individuals for the purpose of scholarly research.

I further authorize Ryerson University to reproduce this paper by photocopy or by other means, in total or in part, at the request of other institutions or individuals for the purpose of scholarly research.

I understand that my MRP may be made electronically available to the public. 


\title{
THE IMPACT OF GOVERNMENT FUNDING CUTS ON ETHNO- SPECIFIC SETTLEMENT SERVICES IN ONTARIO: THE CASE OF AFGHAN ASSOCIATION OF ONTARIO AND THE AFGHAN WOMEN'S ORGANIZATION
}

\author{
(C) Alina Mohsini, 2017 \\ Master of Arts \\ Immigration and Settlement Studies \\ Ryerson University
}

\begin{abstract}
This study focuses on the importance of ethno-specific immigrant settlement service agencies (ISSAs) for Afghan newcomers, in particular, refugees, and investigates the impact of Canadian government funding cuts on their services in Ontario. Based on secondary data, organizations' archival documents and multi-lingual literature, this research presents the impact of funding cuts on services and service users through a case study of the Afghan Women's Organization (AWO) and the Afghan Association of Ontario (AAO). This research demonstrates that the 2010 sweeping funding cuts terminated AAO's programs, and consistent funding cuts have limited the AWO's programs. Service users, too, confirm the lack of linguistic and culturally competent services, impacting their settlement and integration. This research is guided by the politics of recognition theoretical framework and strives to inform governmental policy, leading to access and provision of essential settlement services for newcomers.
\end{abstract}

Key words: Ethno-Specific, Settlement Services, Government Funding Cuts, Afghan Refugees. 


\section{ACKNOWLEDGEMENTS}

I would like to acknowledge and thank Dr. Idil Atak for her invaluable time, constant support and supervision. I am beyond grateful for your support and assistance through every step of this MRP. I have been extremely lucky to have a supervisor who cared so much about my work, and who responded to my questions and queries so promptly. Your feedback throughout this process was greatly valued and appreciated. I am very much inspired by your immense knowledge. I had a wonderful experience and it has been an honour and pleasure working with Dr. Atak. I could not have imagined having a better supervisor for my MRP.

I also want to thank Dr. John Shields, my second reader, for reviewing my research and for his insightful comments. I am honored that you were able to accept my request to be this MRP's second reader.

I would like to extend a special thank you to Ms. Adeena Niazi, Executive Director of the Afghan Women's Organization, and Mr. Feroz Hematyar, Executive Director of the Afghan Association of Ontario, for their constant encouragement and support throughout this research project. 


\section{Dedication}

To my family:

My wonderful husband Ahmad Siar Haidary, my kind mother Shafiqa Mohsini, and my lovely kids Isra and Uzayr Haidary. Thank you for your love, support, patience, and being there for me throughout this process. I will be grateful forever for your love and support. Siar Thank you for helping me reach this stage. 


\section{Table of Contents}

Author's Declaration for Electronic Submission of a Major Research Paper ......ii

Abstract ......................................................................................................... ii

Acknowledgements..............................................................................................

Dedication

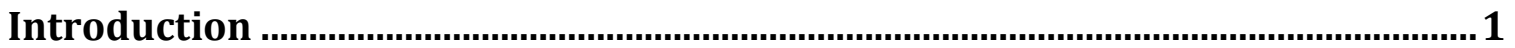

Research Question.....................................................................................................4

Research Significance ...............................................................................................

Theoretical Framework: The Politics of Recognition ................................................

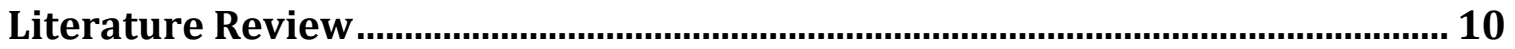

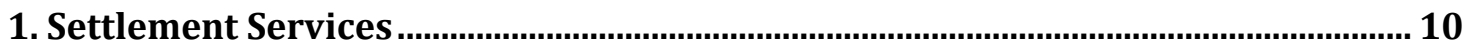

2. The Funding Sources of ISSAs in Ontario..................................................................11

3. A Historical Review of Settlement Services Funding Sources.................................... 13

4. The Vital Role Played by Ethno-Specific ISSAs ........................................................ 16

5. Afghan Migration to Canada and the Importance of Ethno-Specific ISSAs .............17

6. The Afghan Women's Organization ...................................................................18

7. The Afghan Association of Ontario

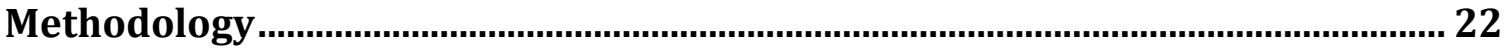

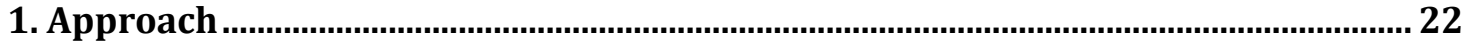

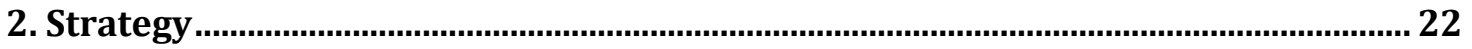

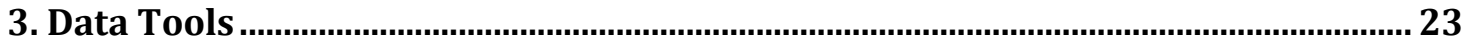

a. Internal Sources: .............................................................................................................................2

b. External Sources:.................................................................................................................22

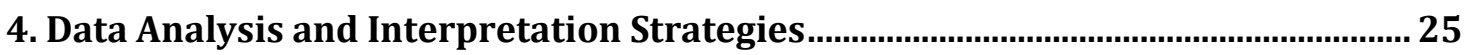

5. Validity and Reliability ................................................................................................. 26

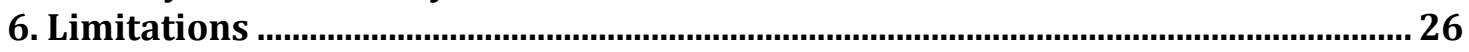

Context, Findings and Discussion ...................................................................... 22

1. Funding Sources of the AWO ............................................................................... 28

2. Summary of Funding Cutbacks....................................................................... 29

3. Funding Sources of the AAO ................................................................................ 31

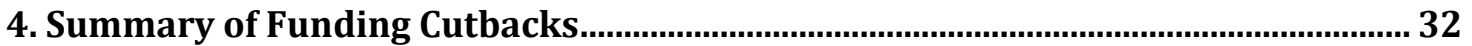

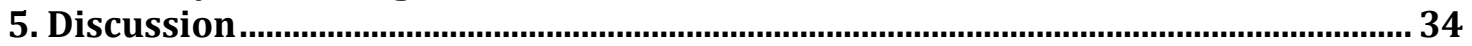

6. The Impacted Services of the AWO by Government Funding Cuts............................36

THEME 1. Language Skills Development Programs ....................................................................39

a. The Importance of Language Skills Development Programs for Afghan Newcomers ........39

b. The Impact of Government Funding Cuts on Language Skills Development Programs ...41

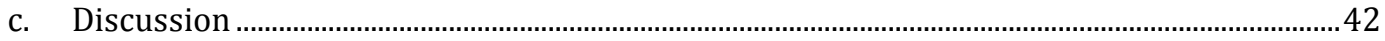

THEME 2. Labour Market Participation.................................................................................... 44

a. The Importance of Labuor Market Participation Programs for Afghan Newcomers .........44

b. The Impact of Government Funding Cuts on Labour Market Participation Programs .....46

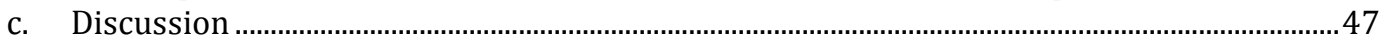

THEME 3. Support Services ...........................................................................................................48

a. The Importance of Support Service for Afghan Newcomers..................................................48

b. The Impact of Government Funding Cuts on Support Services............................................51

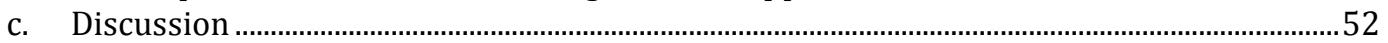


7. The Impacted Services of the AAO by Government Funding Cuts .......................... 53

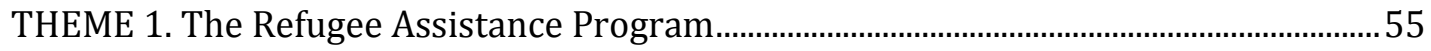

a. The Importance of Refugee Assistance Program for Afghan Newcomers .............................55

b. The Impact of Government Funding Cuts on Refugee Assistance Programs ..........................57

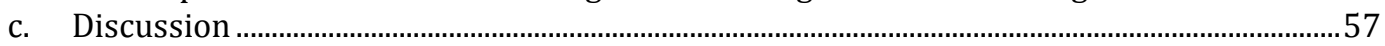

THEME 2. Information, Orientation, and Advocacy Programs..............................................58

a. The Importance of Information, Orientation, and Advocacy Programs for Afghan

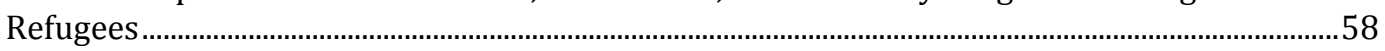

b. The Impact of Funding Cuts on Information, Orientation, and Advocacy Programs .........60

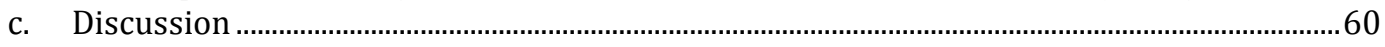

THEME 3. Community Connection and Youth Program ...........................................................61

a. The Importance of Youth Programs for Afghan Newcomers .................................................61

b. The Impact of Government Funding Cuts on Community Connection and Youth

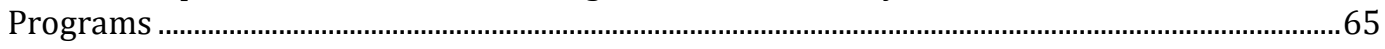

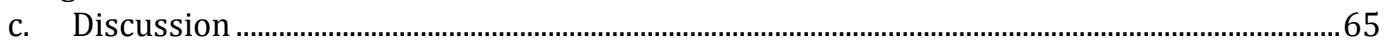

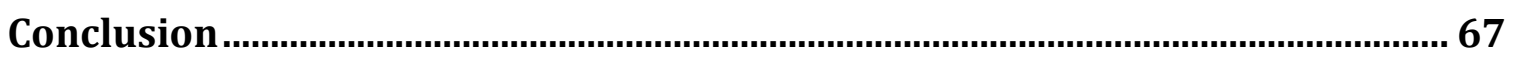

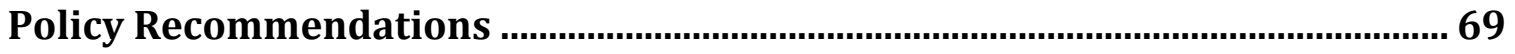

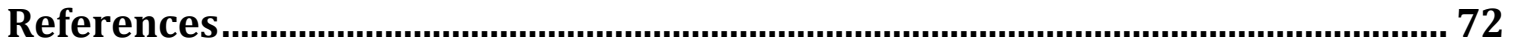




\section{Introduction}

In the past three decades, as a result of the Soviet war, civil war that ensued, as well as the Taliban dictatorial regime, and continuous Taliban insurgencies, close to 9-10 million Afghans have fled Afghanistan and become refugees around the world (Hughes, 2008; Khan, 2016; Ruiz \& Emery, 2001; Ghufran, 2016). These Afghan refugees seek protection from the neighboring countries to Afghanistan including: Pakistan and Iran, which have minimal immigration requirements. However, Pakistan and Iran are not signatories to the United Nations'1951 Convention Relating to the Status of Refugees or to its 1967 Protocol. Hence, both countries provide only temporary protection for Afghan refugees (Ghufran, 2016). Due to this temporary status, Afghan refugees do not have access to public services offered by the Pakistani and Iranian governments, including education, healthcare, and employment in the public sector (Kuschminder and Dora, 2009). Therefore, for permanent protection and stable lifestyle, some Afghan refugees prefer being resettled in developed countries such as Canada. The vast majority of Afghans who migrate to Canada come as refugees through the government-assisted and private sponsorship refugee programs (Burhan, 2015).

The Afghan diaspora in Canada is as large as 80,000 to 120,000 individuals. The majority live in Ontario (Marchand et al., 2014), with 50\% residing in Toronto (Nazar, 2012). According to Statistics Canada, the number of Afghan newcomers to Canada is growing and it is expected to grow with more than 1,000 new arrivals each year (Nazar, 2012), requiring more settlement support. In Toronto, Afghan refugees receive support and settlement services from the already-established Afghan community and the two 
Afghan ISSAs, the Afghan Women's Organization (AWO) and the Afghan Association of Ontario (AAO).

In contrast with many other immigrant communities in Canada, the majority of Afghans are forced migrants. They are a particularly vulnerable population since, prior to their resettlement in Canada, they often experienced or witnessed human rights violations, executions, abductions, physical and sexual violence, or other forms of torture in Afghanistan (Oxfam International, 2009; Nordland, 2012). Furthermore, the majority of these refugees lived in refugee camps and suffered from a lack of access to services such as education and health care. They encounter challenges such as war trauma, language and cultural barriers, and lack of professional education and employment opportunities (Ludin, 2008; Nazar, 2012; Quirke, 2014; Sidiqi, 2012; Kohistani, 2012; Wali, 2012; Ahmed, 2014). In this context, the provision of settlement services is of vital importance for them. They need, in particular, transitional services provided by Afghans in Afghani languages, assisting them to successfully settle and integrate into Canada.

The history of the AAO and the AWO demonstrate that, in the past three decades, these two ISSAs have played a major role in providing culturally and linguistic competent support services, leading to the self-sufficiency, as well as the steady and successful social, cultural, and economic settlement and integration of Afghan newcomers in Canada. The AAO's executive director, Feroz Hematyar, and the AWO's executive director, Adeena Niazi, credit and acknowledge the federal government of Canada for funding their services, contributing to their success in the past three decades (personal communication, March 25, 2017; May 8, 2017). The AAO emerged in the 1980s and the AWO in the 1990s with the aim to meet many Afghan newcomers' 
pressing and immediate needs. However, since 2010, the consistent cutbacks of government funding for settlement services have particularly affected ethno-specific Ontario-based ISSAs, including the AAO and the AWO, serving Afghan newcomers in Canada.

My personal experience highlights how important these Afghan ISSAs' services are for Afghan newcomers. When my mother moved to Toronto, she could not access settlement programs due to language barriers, contributing to her isolation, until she was referred by the Afghan community to access support services at the AAO and the AWO. At these two organizations her needs were immediately assessed and essential services were provided. The services she received were: orientation classes on the use of public services; English language classes; interpretation and translation services; escorts to medical and other appointments; information and referral services to Afghan seniors' programs and recreational programs such as Afghan poetry and art programs organized by these organizations; and employment support. The employment support offered by these ISSAs lead to a job for my mother as an announcer on one of the Afghan TV channels broadcast from Toronto. In addition to these services being provided in Afghan languages, these ISSAs also encouraged the self-sufficiency of clients by providing basic English conversation lessons and one-on-one or group training classes on how to access services independently. My mother was able to access different services from these ISSAs. However, since 2010, due to funding cuts all of these services have been terminated from the AAO, and the AWO — as the only remaining ethno-specific ISSAdoes not have sufficient funds to respond to all Afghan newcomers' needs. These two organizations helped my mother access services and she would not have had a successful 
transition and settlement experience if she had not had access to these services in Afghan languages. As a recipient of the settlement support services from these ISSAs, I would like to draw attention to the vital role played by these organizations and advocate for increased financial support to them.

\section{Research Question}

How did the government funding cutbacks for settlement services impact the services and service users of the Afghan Association of Ontario and the Afghan Women's Organization in Ontario?

\section{Research Significance}

Addressing this phenomenon is a worthy topic of investigation, as access to services supporting settlement and integration is the legal right of newcomers in Canada and the provision of these services is the responsibility of the government. The government funding cuts of the ethno-specific ISSAs contradict the Canadian multiculturalism policy and the objectives of the Immigration and Refugee Protection Act (IRPA) (S.C. 2001, c. 27), and in particular to fulfill Canada's international legal obligations with respect to refugees (s. 3(2)(b)). Canada is a signatory of the 1951 Convention Relating to the Status of Refugees (Refugee Convention), which is first and foremost a human rights instrument that protects a number of fundamental rights and freedoms, including the rights to association, education, health care, wage-earning and professional employment for refugees. In addition, the multiculturalism policy, a Constitutional principle, was adopted by the Canadian government in 1971, which focuses on minority rights, diversity inclusion, and making room for others (Siemiatycki, 2015 , p.103). One of the goals of the multiculturalism policy is providing cultural and 
linguistically competent services for minority groups, and making Canadian "institutions and public funded organizations reflect the multicultural reality" (Canadian Council for Refugees, 1998). Therefore, it is the right of newcomers, in particular refugees, and minority groups to have access to institutions reflecting their culture and ethnicity. The role of the government, as mentioned in the objectives of the IRPA (S.C. 2001, c. 27, section 3), is to support the settlement and integration of refugees and immigrants, and "to support and assist the development of minority official languages communities in Canada" (p. 2). Based on the analysis of the IRPA, it is the government's responsibility to invest in settlement services for immigrants to enhance the accessibility, quality, and reliability of services, promoting their successful settlement and integration. Therefore, it is important to inform policy makers about the problems that government funding cuts pose for these two ethno-specific Afghan ISSAs.

It is argued that as a result of the aforementioned funding cuts, the AAO and AWO did not have sufficient resources and staff to conduct service promotion strategies (personal communication, March 25, 2017; May 8, 2017). Therefore, these ISSAs remain under-resourced and under-served. There is also a scarcity of academic studies and resources in English to show the impact of insufficient funding on services and service users of these ISSAs that could be used to support proposals and inform the government for funding settlement services.

In order to address this problem, my MRP will explore, analyze, and explain the impacts and benefits of services previously provided by these two ISSAs, contributing to the successful settlement and integration experience of Afghan immigrants in Canada. The study will further analyze the degree of government funding cuts, and will 
investigate and explain the impact of funding cutbacks on services and service users of these two ISSAs. This research is based on the analysis of secondary data, including organizational archival data, such as annual reports, demonstrating the impact of funding cuts on the services of organizations. The multilingual, ethnic literature from the Afghan community in Ontario is also used in order to share the Afghan newcomers' perspectives with the government and policy makers, regarding the limitation of services, because otherwise the newcomer point of view has been silenced due to language barriers. This research is guided by the recognition theoretical framework, which emphasizes that in Canada, as a multicultural society, the recognition of newcomers' needs must be based on the affirmative recognition of their ethnic and cultural distinctiveness, leading to the provision of services reflecting their languages and cultures of origin, thereby enhancing their self-sufficiency, settlement and integration processes.

This paper begins with an introduction to the politics of recognition as a theoretical framework. Secondly, it provides a literature review presenting background information and the knowledge gap about the phenomenon. Thirdly, the qualitative case study research methodology is discussed. Fourthly, the findings are presented as themes, bringing to the surface the most negatively impacted services resulting from government funding cuts. For each theme, in-depth discussion is provided, highlighting the importance of the findings. Lastly, this research will conclude with recommendations advocating for the provision of funding for ethno-specific ISSAs, in particular Afghan ISSAs, to provide settlement services for vulnerable newcomers in Ontario.

This study will bring the practical experience of these two ISSAs into an academic study framework, which can be used as background information, evidence, and 
a source for the development of funding proposals and to inform policy makers about the situation. The findings will further provide useful knowledge and raise awareness for anyone interested in issues addressed by this research. This study aims to make a practical contribution to our understanding of ethno-specific ISSAs and the Afghan newcomer community by framing this contemporary phenomenon.

\section{Theoretical Framework: The Politics of Recognition}

This research is guided by the politics of recognition theoretical framework. Taylor (1992) associates recognition with multiculturalism and believes that they both share a common commitment, which is the de-marginalization and inclusion of people who are from different ethnic and cultural backgrounds in a multicultural society (Song, 2016). Recognition acknowledges pre-existing features and the culture of minority immigrants. While multiculturalism, as a policy, grants minority groups rights by which individuals can pursue their cultural practices, recognition brings these rights into action. The pairing of multiculturalism and recognition can protect the uniqueness of immigrants, ensuring their access to services and resources reflecting their ethnicity and culture, and promoting their inclusion in society (Malloy, 2014; Rodrigues, 2017). Coulthard's (2007) theory of recognition advocates for "cultural recognition of sub-state groups that have suffered at the hands of political power" (p. 443), and just distribution of resources and services for all minority groups in society. According to Malloy (2014), recognition theorists believe that "recognition remains an attractive end for those interested in multiculturalism, and the possibility of living a just life in an ever-expanding world" (p. 416). 
This theory is selected because the recognition of immigrant minority groups' rights, needs, and differences by the government can lead to the provision and access of cultural and linguistic competent services. In Canada, the multiculturalism policy is adapted to ensure minority groups' rights, cultural differences, and fair access to services. However, it is often perceived to exist as a "theory not practice" (Gana, 2009, p. 21), and "accommodating difference" has become entrenched in the notion that newcomers should now adapt to a pluralistic value system, shrinking government's responsibilities. Therefore, recognition emphasizes the state's and civil society's role in ensuring "affirmative recognition of societal cultural differences ... and the freedom and wellbeing of marginalized individuals and groups living in ethnically diverse states" (Coulthard, 2007, p. 436), bringing the multicultural theory into practice. The literature asserts the multi-dimensional benefits of the ethno-specific ISSAs for the well-being of newcomers. Thus, recognition of this fact by the government and policy makers can lead to the provision of services enhancing newcomers' settlement and integration processes. The politics of recognition rejects the policy of assimilation, and focuses on the affirmative recognition of societal cultural differences. Coulthard (2007) argues that it is the state that negotiates recognition by acknowledging its peoples' needs and the fair distribution of resources and services to accommodate their distinctiveness.

Further, it is argued that recognition determines people's sense of who they are, therefore positive and negative recognition has a direct impact on shaping people's selfawareness and life. The justice of recognition, which is providing resources and services based on immigrant minority groups' needs, means positively recognizing them as part of society (Coulthard, 2007). This can contribute to immigrants' sense of belonging in their 
new community, thus facilitating their integration. Misrecognition occurs by discounting immigrant minority groups' needs and their cultural and linguist component services. Thus it contributes to building a sense of otherness, inferiority, and resistance to integration. In addition, research shows that feelings of self-worth, self-respect, and selfesteem are possible only if people's culture, needs, and skills are positively recognized and accommodated by the state and host society; misrecognition can "inflict harm, can be a form of oppression, imprisoning one in a false, distorted, and reduced mode of being" (Coulthard, 2007, p. 442). Thus, recognition constitutes a "vital human need" (Taylor, 1992, 26).

Goksel (2014) notes that immigrants cannot integrate into society unless "the recognition order of the host society provides normative conditions such as equal respect, esteem for its immigrants' healthy self- realization," (p. iii), and cultural and linguistic competent services offered by the ethno-specific ISSAs. Immigrants need cultural and linguistic component services reflecting their ethnicity while they are negotiating their new identity by learning the language and adapting the culture of a new society. Recognition theorists believe that minorities should be "considered eligible for some form of recognition capable of accommodating their cultural distinctiveness" (Coulthard, 2007, p. 442); this can facilitate their settlement, integration, and inclusion in a new society (Toylar, 1992). Thus recognition becomes an important theory and practice in a multicultural society such as Canada.

This transformative worldview is used because this research promotes the recognition of minority newcomer groups and underlines the importance of ethnospecific ISSAs in enabling these groups to settle and integrate into Canada. Therefore, it 
"contains an action agenda" (Creswell, 2014, p. 9), and pleads for government funding policy reform in favor of ethno-specific ISSAs. It argues that such reform is vital for the well-being of marginalized newcomers, and in order to bring a positive change in newcomers' lives.

\section{Literature Review}

\section{Settlement Services}

Settlement service programs help immigrants make and bring necessary adjustments in their lives, while in the host country. These services focus on helping immigrants have a steady transition in a new country and support their economic and societal participation. The settlement services are mainly divided into three processes: adjustment, which involves getting familiar with the new culture and environment; adaptation, which is the process of understanding to manage the new changes; and lastly, integration, which involves immigrants' contribution to the economic, social, political, and cultural aspects of the new society without any barriers (Shields et al., 2016). The Canadian Council for Refugees presents this process in Table 1.

\begin{tabular}{|l|l|l|}
\hline Dimension & \multicolumn{1}{|c|}{ Short-term (settlement) } & \multicolumn{1}{|c|}{ Long-term (integration) } \\
\hline Economic & $\begin{array}{l}\text { Entering job market } \\
\text { Financial independence }\end{array}$ & $\begin{array}{l}\text { Career advancement and income parity } \\
\text { Entry into field of prior employment }\end{array}$ \\
\hline Social & $\begin{array}{l}\text { Established social network } \\
\text { Diversity within social network }\end{array}$ & $\begin{array}{l}\text { Accessing institutions } \\
\text { Engaging in efforts to change institutions }\end{array}$ \\
\hline Cultural & $\begin{array}{l}\text { Adaptation of various aspects of lifestyle (e.g. } \\
\text { Diet) }\end{array}$ & $\begin{array}{l}\text { Engaging in efforts to redefine cultural identity } \\
\text { Adapting or reassessing values }\end{array}$ \\
\hline Political & Citizenship and voting & $\begin{array}{l}\text { Participation in political parties } \\
\text { Participation in socio-political movements }\end{array}$ \\
\hline
\end{tabular}

Table 1. Indicators of Settlement and Integration (Canadian Council for Refugees, 1998)

The organizations that provide a range of programs that address the challenges newcomers face, and are responsible for delivering settlement support, are ISSAs (Canadian Council for Refugees, 1998). Therefore, as defined, settlement services and 
agencies are essential to the needs of immigrants, which contribute to their comfort and success while settling in a new society. The range of settlement services is shown in Table 2.

\begin{tabular}{|l|l|l|l|}
\hline \multicolumn{4}{|c|}{ Settlement Services } \\
\hline 1. Advocacy & 5. Counseling and support & 9. Emergency food services & 13. Recreation \\
\hline 2. Employment & 6. English as a second language & 10. Information/ referral & 14. Translation/ interpretation \\
\hline 3. Education & 7. Form filing & 11. Legal & \\
\hline 4. Housing & 8. Health/Medical & 12. Orientation & \\
\hline
\end{tabular}

Table 2. Settlement Services in Canada (Lim et al., 2005)

\section{The Funding Sources of ISSAs in Ontario}

The federal government provides funding for seven streams of settlement services, shown in Chart 1 . These programs are delivered by both the mainstream and ethno-specific ISSAs. The mainstream ISSAs are large organizations, providing services for all newcomers in Canada, for instance COSTI and WoodGreen Community Services. The ethno-specific ISSAs are often small organizations, providing settlement and support services for newcomers from a specific ethnic group, which take into account service users' ethnic culture and language. Examples of ethno-specific ISSAs are the Arab Community Center of Toronto, AAO, and AWO. All ISSAs must enter into a negotiated contribution agreement with the federal government for each project being funded. This is a legal document containing articles and schedules that stipulate the terms and conditions of the funding, including planned activities and intended results, eligible costs, terms of payment, data collection, monitoring and reporting. Each contribution agreement can last for three years, with possible amendment and renewal opportunity (Immigration, Refugee and Citizenship Canada, 2014). 


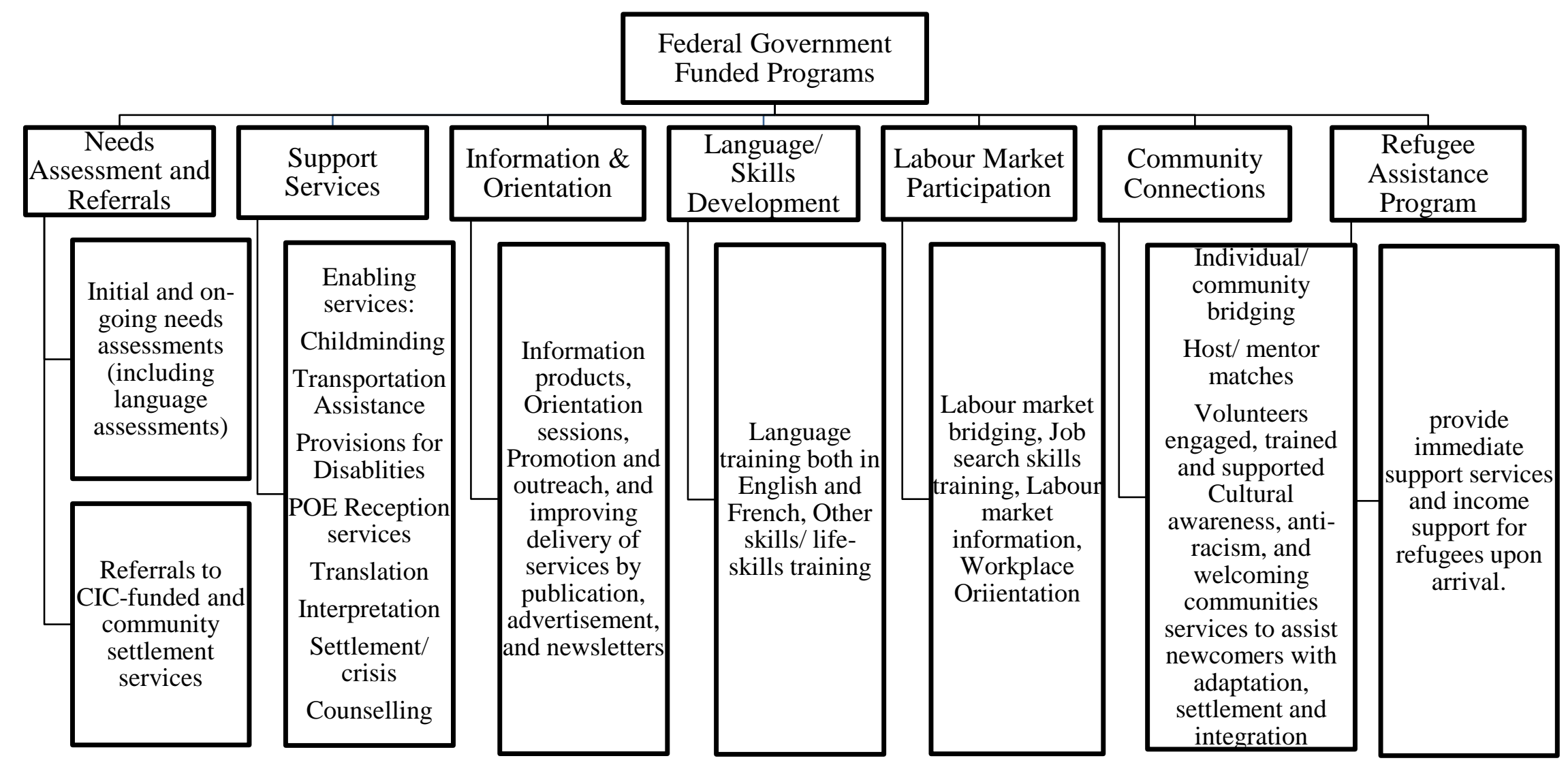

Chart 1. The Federal Government Funded Settlement Service Programs (Lim et al., 2005; Germain, 2008; Ricento et al., 2008) 
The Province of Ontario also funds the Newcomer Settlement Program (NSP).

Through this program, ISSAs help newcomers adjust and contribute to their new communities. However, this contribution is not as large as the federal government fund. The funding streams of this program focus on core assessment and referrals, employment facilitation, and sectorial support project (Ontario Government, 2017).

The municipal branch of government does not have regular funding for settlement services like the federal and provincial branches. The municipal government announces calls for proposals whenever funding becomes available for settlement services. For instance this can happen once a year, twice a year, or every other year (Khwaja, 2016).

The non-government sources, such as foundations, charities, fundraisings, and service fees, may sometimes fill the gap and fund settlement services. These funding sources offer ISSA's some flexibility in terms of services provided and population to serve. However, this short-term funding received from the non-government sources remains insufficient in comparison to the demand for all services and notably the consistent need to provide resettlement programs (Khwaja, 2016).

\section{A Historical Review of Settlement Services Funding Sources}

Since the 1970s, Canada was considered as having the "best practice model of settlement and integration services" (Shields et al., 2016, p. 3) in the world. Khwaja's (2016) study shows that, until the 1990s, as a shared responsibility, the federal and provincial governments were directly in charge of funding and providing settlement services for immigrants. The accessibility, regularity, and steadiness of funding for the government agencies contributed to the quality, stability, and reliability of services. The major milestones in the settlement services' funding sources are highlighted below. 
In the 1980s the government funding policies for settlement services changed. The federal and provincial governments gradually decreased their role in directly providing settlement services to immigrants, and transferred the responsibility to non-profit organizations (Sadiq, 2004). The main purpose of this decision was that nonprofit ISSAs were often located near newcomers residential areas, therefore they were better positioned to know the needs and to service immigrants (Shields et al., 2016). The government provided ISSAs with sufficient funding to self-design and deliver settlement services to immigrants. The peak of government funding for ISSAs was in 1994, as about $60 \%$ of all funds for ISSAs came from the government sources, and in Ontario $89 \%$ of funding for settlement services was provided by the government (Richmond \& Shields, 2004). Both the large ISSAs and small ethno-specific ISSAs benefited from the funding. In 1996 the emergence of neoliberalism contributed to decentralization of the government and privatization of settlement services (Shields et al., 2016). This was meant to increase the "role of the private institutions of society in satisfying people's needs" ( $p$. 15). Transferring settlement services delivery to ISSAs, through the utilization of a cheaper nonprofit, and often non-unionized workforce, is a key component of neoliberal agendas (Flynn and Bauder, 2014; Shields et al., 2016).

Consistently, since 1996, major funding policy shifts occurred contributing to government funding limitations for ISSAs. The government introduced a competitive system of short-term funding contracts through the Purchase of Service Agreement (Sadiq, 2004). The government initiated this process to encourage ISSAs to compete with each other in developing plans to provide "good fast and cheap services" (Richmond \& Shields, 2004) in order to secure government funding. However, the controlled funding, 
increased accountability requirements, quarterly reporting, with little or no flexibility in program delivery or funding (Eakin, 2001), place a significant administrative burden on ISSAs (Sadiq, 2004). This process has affected the small ethno-specific ISSAs the most, because they lack administrate support and resources to regularly compete for these short-term contracts with large ISSAs. Sadiq (2004) finds that when it comes to biding the government for funding, it is always the larger agencies that win the contracts. Additionally, the matching contribution-funding policy was introduced by the government. Based on this policy, the government provides part of the funding for the ISSAs' settlement service projects, requiring the ISSAs to find other sponsors to contribute and fill the balance. This also requires ISSAs to find other sponsors before applying for matching contribution funding (Eakin, 2001). Through this initiative, the government encourages private sponsors to fund settlement services. This policy requirement further limits ethno-specific ISSAs' access to government funding, as they do not have sufficient resources and staff to reach out to other sponsors. These funding limitations significantly affect resettlement service provisions. According to Sadiq (2004), in Ontario, 20\% of large ISSAs and 40\% of small ISSAs reported funding cuts and $43 \%$ of settlement service programs were eliminated by the end of 2006.

The major government funding cutbacks for ISSAs in Ontario occurred in 2010, as "the federal government announced $\$ 53$ million in cuts to settlement services — and \$44 million of that was pulled out of Ontario" (Pagliaro, 2010, p. 1). The majority of funding cutbacks happened in Ontario and they were justified on the basis of decreased immigration to the province (Voices, 2012; Immigration, Refugee, and Citizenship Canada, 2012). As a result of the 2010 funding cuts in Ontario, 200 ISSAs reported 
funding cuts, 28 agencies reported services elimination, and 13 ethno-specific ISSAs were closed down, such as the AAO, Ethiopian Association, Eritrean Canadian Community Centre, and South Asian Women's Centre (Keung, 2010). This led ISSAs to rely on volunteer services and charitable funding to fill the gap (Shields et al., 2016), often contributing to unreliability, instability, and low quality of services. For instance, volunteers are often not professionals in the field in which they deliver services, and further, they are not required, like paid employees, to regularly be present to deliver the services (Sadiq, 2004). According to Mukhtar et al., (2016) the government's expectation of efficiency of services often conflicts with client desires for quality service, and this process often serves the need of the supplier (government) rather than the consumers (newcomers).

Recently, between 2015 to 2016, 47 organizations reported funding cuts in Ontario, resulting in $55 \%$ of staff layoff and $36 \%$ of service hour reduction, which affected the ethno-specific ISSAs the most (OCASI, 2016). The neoliberal restructuring of non-profit services has caused a crisis in the sector as providers are forced to do more with less. In this process "programs have been eliminated, service quality has deteriorated, and many smaller agencies have been forced to close" (Richmond and Shields, 2004, p. 18). Based on the literature review the funding cutbacks affected ethnospecific ISSAs the most.

\section{The Vital Role Played by Ethno-Specific ISSAs}

Ethno-specific agencies provide initial services to emerging newcomer communities that large agencies cannot (Sadiq, 2004, p. 6). Literature confirms the benefits of ethno-specific organizations, such as providing linguistically and culturally 
sensitive services, having the best outreach practices through community leaders and by advertising in ethno-specific press outlets, hence, reaching vulnerable immigrants who are often isolated and lacking trust. The ethno-specific ISSAs also act as a source to offer newcomer employment and volunteer experience which contributes to the professional development of newcomers that would otherwise be socially, linguistically and geographically difficult for newcomers to access. (Sadiq, 2004; Zhao, 2009; Shields et al., 2016). Shields et al. (2016) study finds that "ethno-specific nonprofit organizations emerged as a result of a lack of response to many newcomers' pressing and immediate needs" (p. 20) by the other settlement agencies. In addition to the multi dimensionality of support, the ethno-specific ISSAs services often have "no expiry date and no eligibility requirement" (Zhao, 2009, p. 7) meaning newcomers from that specific ethnic group can always access the services. Khwaja (2016) finds that newcomers who receive settlement services from the ethno-specific ISSAs tend to be better integrated into the host society and have acquired social capital assets in contrast to similar immigrants who did not have access to such services. Overlooking these benefits by funding cuts and the elimination of services, negatively impacts settlement and the integration of newcomers.

\section{Afghan Migration to Canada and the Importance of Ethno-Specific ISSAs}

Afghan migration to Canada started in 1979, when Afghans fled the Soviet'

invasion of Afghanistan. Almost all Afghans who migrated to Canada in the 1980s came as resettled refugees from Pakistan (Burhan, 2015). The Canadian Census data shows that between 1979 and 1989, 5,390 Afghans were resettled in Canada (Ghafour, 2015). The second wave of Afghan migration started in 1989 and lasted until 2001, when Afghans fled the civil war and the Taliban's oppressive regime. Burhan's (2015) study finds that 
the second wave of Afghan migrants came through the government assisted refugee program, the privately sponsored refugee program, and the family reunification class facilitated by family members already in Canada. Between 1989 and 2000, 26,560 Afghans were settled in Canada (Ghafour, 2015). The third wave of Afghan migration to Canada includes those fleeing from Afghanistan because of Taliban insurgencies from 2001 to the present. Since 2001, two more patterns are provided for Afghans to immigrate to Canada, as shown in Table 3, contributing to the increased number of Afghan migrants in Canada:

\begin{tabular}{|l|l|}
\hline Immigrant Category & $\begin{array}{l}\text { The government refugee assisted program } \\
\text { The privately sponsored refugee program } \\
\text { The family reunification }\end{array}$ \\
\hline In-land Asylum Seekers & $\begin{array}{l}\text { Afghans who came to the US, under the state department-sponsored } \\
\text { temporary stay programs, cross the border to Canada, and seek asylum }\end{array}$ \\
\hline Special Immigration Measures & $\begin{array}{l}\text { Government protection and resettlement of translators, interpreters, and } \\
\text { Afghan nationals employed by, or on behalf of, Canada in Afghanistan }\end{array}$ \\
\hline
\end{tabular}

Table 3. The current migration patterns of Afghans to Canada (Burhan, 2015)

The majority of Afghans in Canada are first-generation immigrants, with a small percentage of second-generation, requiring more and pro-longed settlement services (Ludin, 2008).

\section{The Afghan Women's Organization}

The AWO was established in1990 in Toronto. Initially, the organization was entirely volunteer-run by its founder, Adeena Niaizi, and a handful of refugee women from Afghanistan. The AWO emerged as an ethno-specific ISSA, but soon extended its services to all newcomers from different ethnic backgrounds. Currently The AWO serves clients from Afghanistan, Syria, Iraq, Pakistan, Iran, and from other regions including Central Asia, the Middle East, South and East Asia, Africa, and Europe. The AWO has been recognized by many prominent organizations including the premier of Ontario, 
Kathleen Wynne, the Minister of the Status of Women of Canada, Maryam Monsef, members of the Canadian parliament, the UNHCR, and the Muslim Welfare Center. The AWO has been credited with improving newcomers' quality of life, helping them live in dignity and reaching their full potential, while promoting their social and economic inclusion into Canada (AWO, 2017; Khan, 2017).

The AWO's services are distinct from other agencies, including the AAO, because the AWO provides a variety of services based on the special needs of refugees and women. The AWO is unique in that it has been very successful in the resettlement and integration of newcomer refugees and specifically women across Ontario. Thus, many newcomer refugees from different ethnic backgrounds, and especially women, feel comfortable to access the services provided by the AWO.

The AWO' vision statement is "refugees and immigrants, especially those who have experienced wars and persecution, leading self-sufficient and dignified lives in a socially inclusive society" (AWO, 2017, p. 1). The AWO's mission statement is:

AWO works with refugees and immigrants, particularly those who have experienced wars and persecution, with a special focus on women and their families. Its mission is to improve their quality of life and to promote their social and economic inclusion in order to enable them to become contributing members of society and to live in dignity. (AWO, 2017, p. 1)

Since 1996, the AWO has sponsored 3,100 Afghan refugees, and offered a variety of settlement and support services as shown in Table 4 and Table 5:

\begin{tabular}{|l|l|l|l|}
\hline \multicolumn{5}{|c|}{ Settlement Services } \\
\hline 1. Advocacy & 7. Counseling and support & 13. Afghan seniors services & 19. Summer camp \\
\hline 2. Employment & 8. English Language Classes & 14. Afghan youth program & 20. Refugee sponsorship \\
\hline 3. Education & 9. Form filing & 15. Legal consultation referral & 21. Information/ referral \\
\hline 4. Housing & 10. Translation/ interpretation & 16. Afghan cultural events & 22. Accompaniment \\
\hline 5. Recreation & 11. Healthy living & 17. Cashier training & $\begin{array}{l}\text { 23. Aggregation } \\
\text { replacement therapy }\end{array}$ \\
\hline 6. Orientation & 12. Driving classes & 18. Home-based day care & \multicolumn{2}{l}{ 1. }
\end{tabular}

Table 4. List of Settlement Services Offered by the AWO (AWO, 2017) 


\begin{tabular}{|l|l|l|l|}
\hline \multicolumn{5}{|c|}{ Community Connections Program for Women } \\
\hline 1. English conversation circle & 5. Transportation & 9. Parenting sessions & 13. Youth sessions \\
\hline 2. Rights and freedoms & 6. Taxation & 10. Homework club & 14. Citizenship classes \\
\hline 3. Canadian law and the justice system & 7. Senior sessions & 11. Stress management & 15. Women's circle \\
\hline 4. Health, mental health & 8. Financial literacy & 12. Life in Canada & \\
\hline
\end{tabular}

Table 5. List of Community Connection Services Offered by the AWO (AWO, 2017)

Currently, the organization is run by 88 full-time and 32 part-time employees. Volunteers

play a significant role in providing the majority of services (Report on Services, 2017).

The AWO has four branches in the Greater Toronto Area. The locations and contact

information of the AWO are as follows:

1. AWO North York (Head Office), 789 Don Mills Rd., \# 700 ON M3C 1T5

2. AWO North York, 747 Don Mills Rd., Unit\# 212 ON M3C 1T2

3. AWO Mississauga, 3050 Confederation Parkway, Unit \#302 ON L5B $3 Z 6$

4. AWO Scarborough, 2555 Eglinton Ave. East, \#211ON M1K 5J1

Website: http://afghanwomen.org Phone: 416-588-3585

\section{The Afghan Association of Ontario}

The AAO was established in 1982 by a volunteer team of Afghans, in accordance with the not-for-profit corporation laws. AAO exclusively provides services for Afghan immigrants in Canada. AAO first started to receive government funding, federally and provincially, in 1987 to sponsor Afghan refugees and to provide settlement, adaptation, and integration services for Afghan immigrants in Canada (Hematyar, 2017, p. 1).

The AAO has sponsored over 16,000 Afghan refugees since 1985, and used to provide programs listed in Table 6 to more than 4000 clients per year:

\begin{tabular}{|l|l|l|l|}
\hline \multicolumn{5}{|c|}{ Settlement Services } \\
\hline 1. Advocacy & 6. Counseling and support & 11. Afghan seniors services & 16. Afghan newspapers \\
\hline 2. Employment & 7. English as a second language & 12. Afghan youth program & 17. Refugee sponsorship \\
\hline 3. Education & 8. Afghan women program & 13. Legal consultation & 18. Information/ referral \\
\hline 4. Housing & 9. Translation/ interpretation & 14. Orientation & 19. Recreation \\
\hline 5. Form filing & $\begin{array}{l}\text { 10. Organization of annual } \\
\text { Afghan cultural events }\end{array}$ & $\begin{array}{l}\text { 15. Radio and TV shows in } \\
\text { Afghan Languages }\end{array}$ & \\
\hline
\end{tabular}

Table 6. List of Settlement Services Offered by the AAO (Report on Services, 2017) 
The mission statement of AAO is "to provide easy access to quality social and community service with professionalism and integrity" (AAO Annual Report, 2010, p. 8). The organization's vision is to "aspire to build sustainable, sound, safe, balanced and dynamic civic communities of highest standards for Afghans in a diverse environment conducive to their growth, development, and well-being a legitimate and integral part of Canadian society" (p. 9).

The AAO used to have over 30 full and part time employees, providing services. Currently, the AAO runs its programs by two full-time employees providing settlement counseling for newcomers, and operates the private refugee sponsorship program for Afghans. Student internees and volunteers play a major role in delivering services for the AAO clients (Hematyar, 2017). The organization's location and contact information are as follows:

Address: 130 Bridgeland Avenue, Suite \#202 North York, ON M6A 1Z4 Canada. Website: http://www.aaocanada.ca Phone: 4167449289

The literature reviewed explained the funding system of settlement services in Canada. Further, it demonstrated the government consistent funding cuts for ISSAs, in particular the ethno-specific ISSAs. The literature asserted the importance of ethnospecific ISSA's services, in short-term and long-term adaptation, settlement, and cultural, social, and economic integration of newcomers. Lastly, it found that studies generally discussed the government funding cuts for settlement services, but no case studies of affected organizations were identified, focusing on the impact of these funding cuts on services and service users of the organizations. The study of the impacts of funding cuts would reveal a lack of important and needed settlement services, contributing to the 
unsteady settlement and integration process of newcomers, which would then inform policy and funding for service providers. This leads to my research interest to conduct a case study of two ethno-specific organizations, the AAO and the AWO, to identify the impact of government funding cuts on services and service users.

\section{Approach}

\section{Methodology}

A qualitative approach is used for this research since this study is focused on a topic that lacks research (Creswell, 2014). Although many publications, such as Nusrat's (2015) study, discuss the phenomenon of lack of cultural and linguistic settlement services for Afghan newcomers in Afghan languages, the scarcity of information in English has created a knowledge gap, which is addressed by this study through inclusion of multi-lingual information. Further, such an approach allows the analysis and interpretation of secondary data to understand the meanings documents ascribe to the phenomenon of government funding cuts for ethno-specific ISSAs. In addition, this research aims to explore and create an agenda for change and reform, which makes the qualitative approach a good fit for this study (Creswell, 2014).

\section{Strategy}

The explanatory case study is used as a strategy to investigate and explain this contemporary problem of funding cuts for ethno-specific ISSAs, impacting newcomers, through detailed contextual analysis of two specific case studies, the AAO and the AWO. This research examines the data closely both at a surface and deep level in order to explain the problem — the best fit for an explanatory case study strategy (Zainal, 2007). 


\section{Data Tools}

\section{a. Internal Sources:}

This research is based on the secondary data. The set of data which is used to discover the impact of funding cuts, since 2010 to present, on services of the AAO and AWO are the archival organization records as shown in Table 7 and Table 8:

\begin{tabular}{|l|l|}
\hline \multicolumn{2}{|c|}{ Data from the AAO } \\
\hline 1 & Annual Report 2010 \\
\hline 2 & Voices 2012 (Funding Cut Report) \\
\hline 3 & Funding Proposal 2016 \\
\hline 4 & Final Report February 2016 \\
\hline 5 & Final Report June 2016 \\
\hline 6 & Report on Services 2017 \\
\hline
\end{tabular}

Table 7. The AAO's Archival Organization Records

\begin{tabular}{|l|l|}
\hline \multicolumn{2}{|c|}{ Data from the AWO } \\
\hline 1 & Annual Report 2009 \\
\hline 2 & Annual Report 2010 \\
\hline 3 & Annual Report 2011 \\
\hline 4 & Annual Report 2012 \\
\hline 5 & Annual Report 2013 \\
\hline 6 & Annual Report 2014 \\
\hline 7 & Annual Report 2015 \\
\hline 8 & Annual Report 2016 \\
\hline 9 & The AWO’s Statement of Operations 2015 \\
\hline 10 & Report on "How Are We Doing?" 2016 \\
\hline 11 & The AWO Profile 2016 \\
\hline 12 & Funding Proposal 2016 \\
\hline 13 & Report on Services 2017 \\
\hline
\end{tabular}

Table 8. The AWO's Archival Organization Records

\section{b. External Sources:}

Secondary data from Nusrat's (2015) research, which explores the lack of services essential for the Afghan community, is also used in this research. Her research was conducted in the Dari and Pashto languages and took place in the Afghan Islamic Community of Canada. Her aim was to address the AWO's and AAO's lack of settlement services after 2010 funding cuts, in order to coordinate informal settlement services for 
vulnerable Afghan newcomers in the Afghan Islamic Community of Canada. Her data and findings are translated into English and are used for this research. Nusrat's research data demographics are presented in Table 9:

\begin{tabular}{|l|l|l|}
\hline Afghan Participants & Gender & Immigrated to Canada \\
\hline 7 & Female & Before 2010 \\
\hline 10 & Male & Before 2010 \\
\hline 6 & Female & After 2010 \\
\hline 11 & Male & After 2010 \\
\hline 34 & Male \& Female & Altogether \\
\hline
\end{tabular}

Table 9. Data Demographics (Nusrat, 2015)

In addition, multi-lingual, Dari, Pashto, and English, literature is used to support the secondary data. It is important to consider and include multi-lingual literature and data, such as Nusrat's (2015) research, because they give voice to Afghan immigrants who have been affected by the limitation and termination of settlement services, and whose voices have not been heard due to language barriers.

All of these secondary data are publicly available, that can be accessed online and hard copies are available at the organizations. Secondary data is used because it has been established by professionals and has been peer reviewed before publication, contributing to its credibility, transparency, and trustworthiness. These secondary data are also easily accessible and time-saving; therefore, the researcher saves time on data collection and instead uses the time on in-depth and accurate analysis of the data. Further, secondary data allows comparison between the past information and the present events in order to reveal impacts of the funding cuts. Each of the reports and proposals from the organization highlight the funding cuts and their impacts. However they have never been analyzed and studied altogether to address the questions asked in this research. In addition, several literature sources about this problem are already published and available 
in Afghan languages, but they need to be translated and analyzed in English in order to effectively and practically utilize this previous research. Therefore, in this case, it is more prudent and time efficient to use this secondary data instead of collecting primary data.

\section{Data Analysis and Interpretation Strategies}

The analysis strategy is the case study explanatory method guided by research questions. In this context, explanatory method "refers to the process of building a set of causal links about how or why something happened" (Baskarada, 2013, p. 11). Two ethno-specific ISSAs, AAO and AWO, are the units of analysis. The secondary data collected, about the case studies, are compared against research questions, and data collection and analyses are developed together until the research questions are answered (Kohlbacher, 2006; Cheng and Phillips, 2012). This process involves: developing categories based on the research questions, such as impacted services and degree of funding cuts for each organizations; and according to each category, data is reviewed, summarized, and transcribed in a text-based format. Further, a secondary data content coding is conducted (Tania, 2014). In the coding process, the transcribed data is reviewed and condensed into sub-categories such as the most impacted services and annual funding variation for settlement programs of the AAO and AWO. Lastly, it brings three major themes for each case study to the surface: Language Skills Development Programs, Labour Market Participation Programs, and Support Service for the AWO; and Information, Orientation and Advocacy Programs, Community Connection and Youth Programs, and Refugee Assistance Programs for the AAO (Neuman, 2004). Later, themes are sorted into categories relevant to the description of a phenomenon (Boyatzis, 1998). At last, an explanatory narrative method is used to summarize and establish 
meanings and significance of findings through a discussion, which links the findings and themes explicitly to the theoretical framework, literature review, and practical issues in the field.

Throughout this process, self-memoing is used to record research notes on interpretations of patterns found in the data, or general comments on issues revealed during the analysis (Baskarada, 2014, p. 12), ensuring that the analysis of evidence obtained answers to some of the initial questions as unambiguously as possible.

\section{Validity and Reliability}

Construct, internal and external validity is ensured by including relevant evidence from multiple secondary sources, containing different perspectives on this matter. Further, consistent cross-checking of the results is conducted in order to achieve internal coherence of finding during data analysis. In this research, the adaptation of a structured case study strategy, properly abidance to the research method, and the creation of orderly folders containing accurate evidence and data adds to the reliability of research. This contributes to similar results if the same operation of study is repeated (Maxwell, 2009; Christie et al., 2000; Collingridge and Gantt, 2008).

Debriefing by the research supervisor and by peers with relevant subject matter expertise takes place in all stages of the research process (Yin, 2003; Troster, 2016). The review and corrections made through this process enhance the accuracy of the case studies, contributing to credibility and trustworthiness of results.

\section{Limitations}

In this study two limitations are noted. First, the two case studies specifically focus on two ethno-specific organizations serving Afghan newcomers. Therefore, the 
findings apply only to these cases' context. The conclusions from the cases cannot apply directly to another case because no two cases are identical (Tesol, 2017). However, the logic of reasoning by analogy can apply in other settings where "it allows the application of lessons learned in one case to another population or set of circumstance" (Rossman and Rallis, 2003). For instance, impacts of government funding cuts apply to other ethnospecific organizations serving similar populations.

Secondly, this study uses secondary data. Therefore, the limitation of this study is the absence of primary data from service providers and users to know their direct perspectives on how the funding cuts affected resettlement services. The aim for this study was to have a prolonged engagement analyzing the already established secondary data in the field in order to produce useful background information and accurate findings and present them to the organizations from which the data was collected. Therefore, due to limited time in this research project only one source of data is used. At this stage, the research focuses on the secondary data. Further research including primary data could strengthen this research and could add more knowledge to the topic specific literature, if time permitted.

\section{Context, Findings and Discussion}

In the following section, the findings generated through the secondary data are presented. First, the data about the AWO's and AAO's funding sources and the federal government funding cutbacks since 2010 is analyzed. Secondly, the affected services of the AWO are presented. During the data analysis, categories emerged based on the affected services, and the most affected services are selected as the following themes: Language Skills Development Programs, Labour Market Participation, and Support and 
Counseling Services. Thirdly, the most affected services for the AAO are selected as separate themes-Refugee Assistance Program, Information, Orientation, and Advocacy Programs, and Community Connection and Newcomer Youth Programs. Under each theme the contexts, including the importance of settlement programs and the degree of government funding cut impacts on these services, are explained, ending with a discussion.

\section{Funding Sources of the AWO}

Since 1990 the AWO delivered federal government funded settlement programs, serving newcomers in Ontario, particularly Afghan refugees (Annual Report, 2010). The funding sources of the AWO's services are presented in Chart 2:

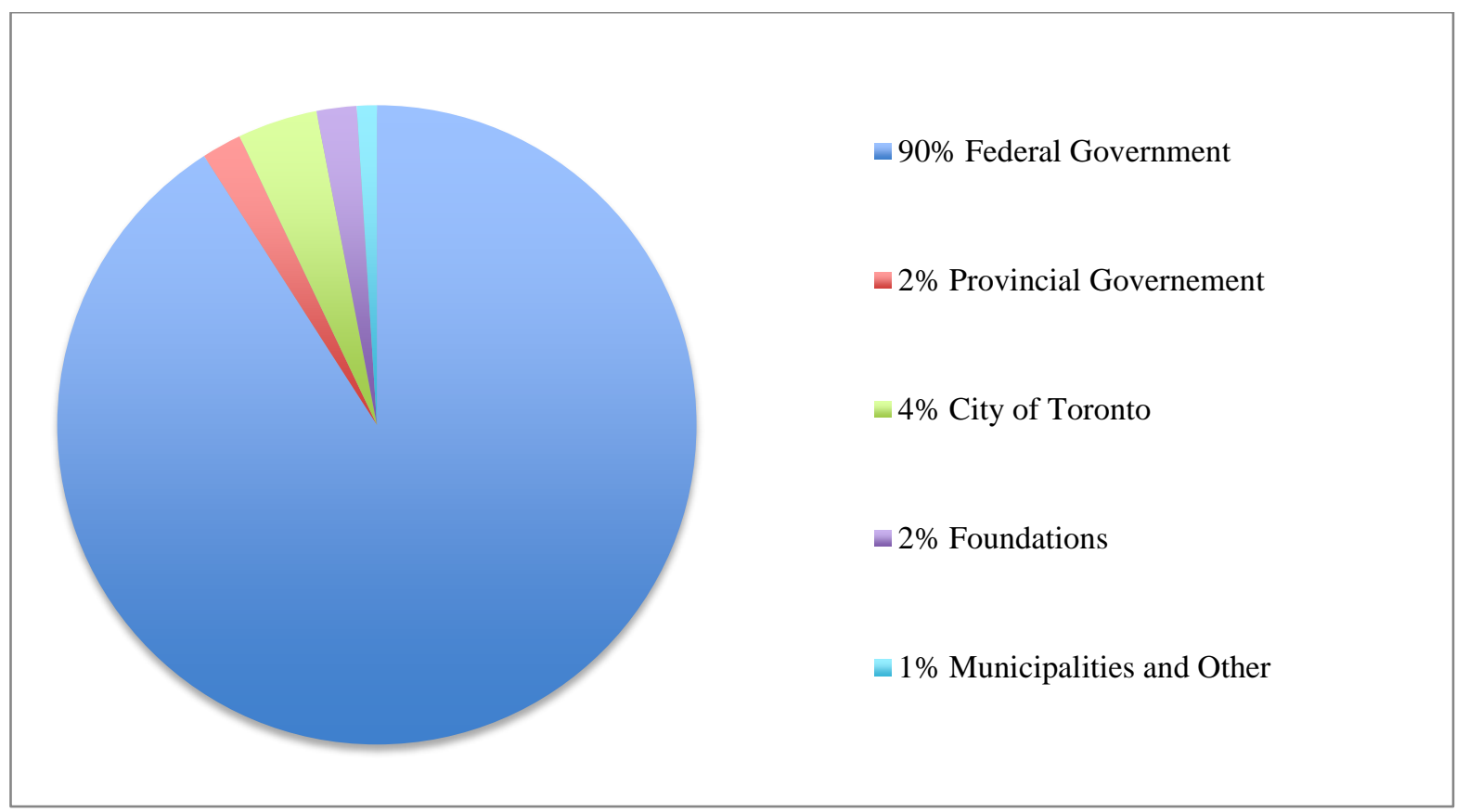

Chart 2. Funding Sources of the AWO (Annual Report, 2013; Statement of Operation, 2015)

Among all the sources, the federal government has been the major funder of the AWO's services. Since the initial provision of the government funding in 1990, the AWO's 
funding remained steady or increased in the following years. However, the data shows that the AWO experienced a major government funding cut, which was announced in 2010 and was implemented in 2011. In the following years the AWO remained with insufficient funding despite the fact that the number of AWO's clients increased, thus impacting its services (Report on Services, 2017).

\section{Summary of Funding Cutbacks}

The federal government funding cutbacks are analyzed based on the AWO's revenue, disclosed in annual reports and statement of operation. The federal government provides funding for the AWO in two regions, Toronto and Peel. The total amount of funding that the AWO has been receiving from the federal government for both regions and its variations (cutbacks and increment) are indicated in Table 10 and Chart 3:

\begin{tabular}{|l|l|r|r|r|}
\hline Source & Year & \multicolumn{1}{l|}{ Total Funding } & \multicolumn{1}{l|}{ Variations } & Percentage \\
\hline Federal Government of Canada (IRCC) & $2009-2010$ & $\$ 3,842,923.00$ & $\$ 512,293.00$ (Increase) & $+15 \%$ \\
\hline Federal Government of Canada (IRCC) & $2010-2011$ & $\$ 3,837,414.00$ & $\$ \$ 5,509.00$ (cut) & $-0.10 \%$ \\
\hline Federal Government of Canada (IRCC) & $2011-2012$ & $\$ 3,416,123.00$ & $\$ 421,291.00$ (cut) & $-11 \%$ \\
\hline Federal Government of Canada (IRCC) & $2012-2013$ & $\$ 3,391,963.00$ & $\$ 24,160.00$ (cut) & $-1 \%$ \\
\hline Federal Government of Canada (IRCC) & $2013-2014$ & $\$ 3,483,679.00$ & $\$ 91,716.00$ (slight increase) & $+3 \%$ \\
\hline Federal Government of Canada (IRCC) & $2014-2015$ & $\$ 3,436,178.00$ & $\$ 47,501.00$ (cut) & $-1.30 \%$ \\
\hline Federal Government of Canada (IRCC) & $2015-2016$ & $\$ 3,328,235.00$ & $\$ 107,943.00$ (cut) & $-3.10 \%$ \\
\hline Federal Government of Canada (IRCC) & $2010-2016$ & $\$ 24,736,515.00$ & $\$ 514,688.00$ (cut) & $-13.40 \%$ \\
\hline
\end{tabular}

Table 10. The Federal Government Funding for the AWO from 2010 to 2016 (Statement of Operation, 2015) 


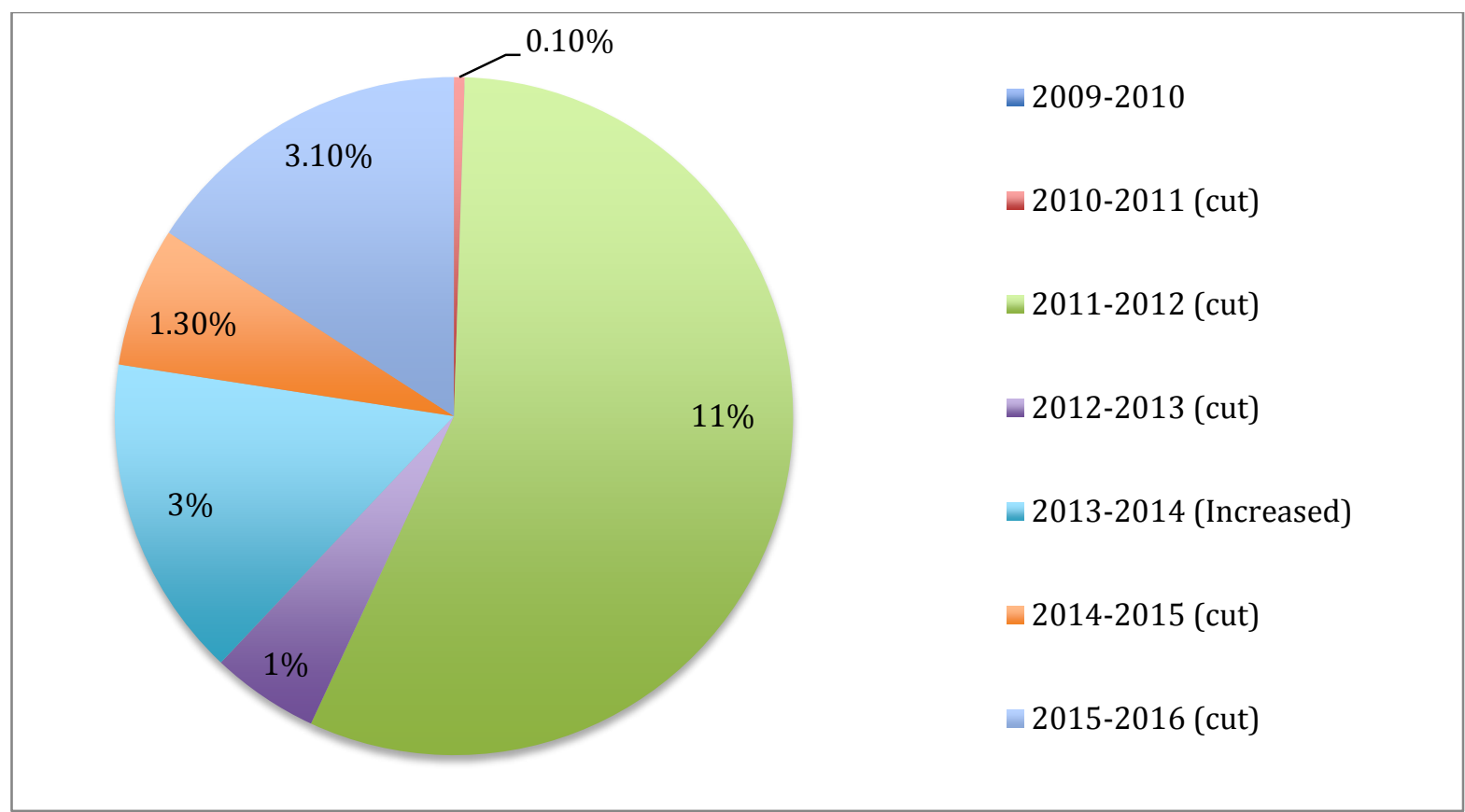

Chart 3. The Total Federal Government Funding Cuts for the AWO (Statement of Operation, 2015)

Based on the data, the AWO lost a major portion of its funding in 2011, and since then faces consistent cuts, except a small increment in 2013, which was again cut back in 2015. Further, data reveals that the Toronto region has been mostly affected by the federal government funding cuts as shown in Table 11 and Chart 4:

\begin{tabular}{|l|l|l|r|r|l|}
\hline Source & \multicolumn{1}{|l|}{ Region } & Fiscal Year & \multicolumn{1}{l|}{ Total Amount } & \multicolumn{1}{l|}{ Variations } & Percentage \\
\hline Federal Government of Canada & Toronto & $(2009-2010)$ & $\$ 2,653721.00$ & $\$ 141,181.00$ & $6 \%$ (increase) \\
\hline Federal Government of Canada & Toronto & $(2010-2011)$ & $\$ 2,525,683.00$ & $\$ 128,038.00$ & $5 \%$ (cut) \\
\hline Federal Government of Canada & Toronto & $(2011-2012)$ & $\$ 2,121,102.00$ & $\$ 404,581.00$ & $16 \%$ (cut) \\
\hline Federal Government of Canada & Toronto & $(2012-2013)$ & $\$ 2,054,646.00$ & $\$ 66,456.00$ & $3 \%$ (cut) \\
\hline Federal Government of Canada & Toronto & $(2013-2014)$ & $\$ 2,110,169.00$ & $\$ 55,523.00$ & $3 \%($ increase) \\
\hline Federal Government of Canada & Toronto & $(2014-2015)$ & $\$ 2,086,700.00$ & $\$ 23,469.00$ & $1 \%$ (cut) \\
\hline Federal Government of Canada & Toronto & $(2015-2016)$ & $\$ 2,027,389.00$ & $\$ 59,311.00$ & $3 \%$ (cut) \\
\hline Federal Government of Canada & Toronto & $(2010-2016)$ & $\$ 15,579,410.00$ & $\$ 626,332.00$ & $25 \%$ (cut) \\
\hline
\end{tabular}

Table 11. The federal government funding for the AWO in Toronto Region from 2009 to 2016 (Statement of Operation, 2015) 


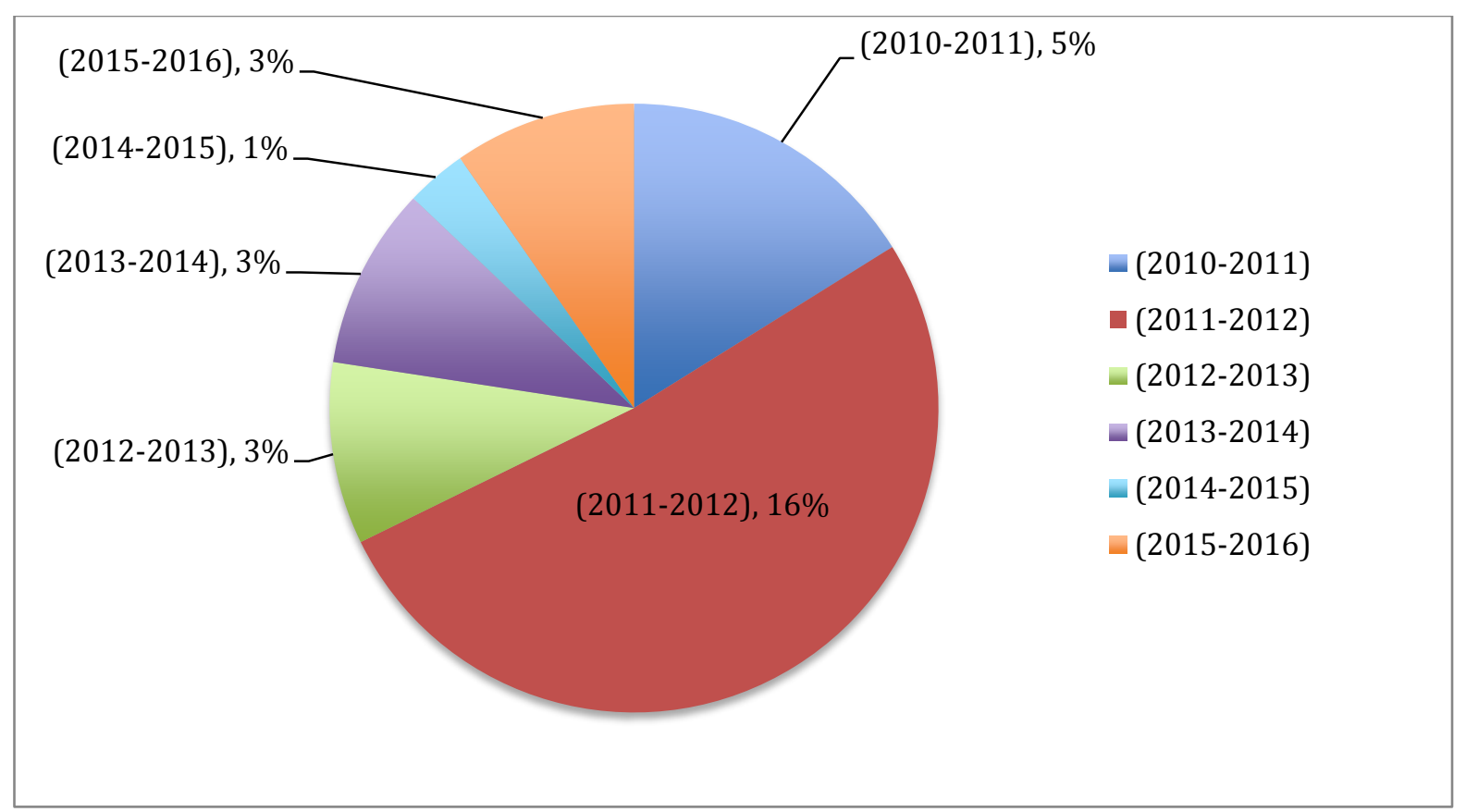

Chart 4. The Federal Government Funding Cuts for the AWO in Toronto Region (Statement of Operation, 2015)

The AWO, in the Toronto region, lost $25 \%$ of its government funding since 2011 . In the fiscal year of 2011, the AWO experienced the largest government funding cut in Toronto.

\section{Funding Sources of the AAO}

Since 1978 the major funder of the AAO was the federal government of Canada, providing $75 \%$ of its funding. The remaining $25 \%$ of the AAO's funding was covered by the provincial government, municipal governments, foundations, and other sources based on a call for proposals as presented in Chart 5: 


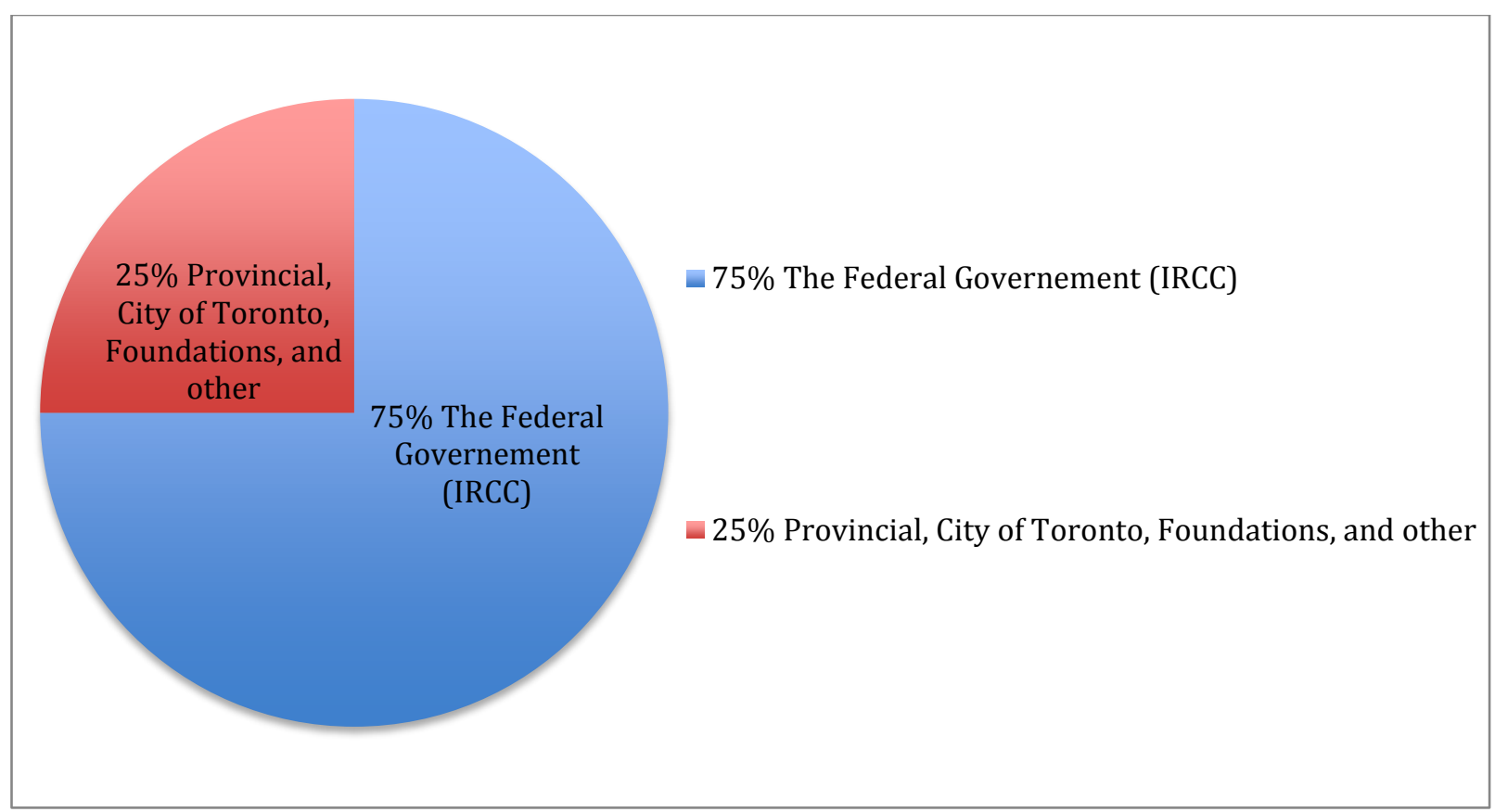

Chart 5. The Funding Sources of the AAO (Annual Report, 2010; Report on Services, 2017)

\section{Summary of Funding Cutbacks}

As the federal government's sweeping funding cuts were announced in 2010, the AAO lost all of its 75\% of federal government funding. Further "in January 2011, AAO received a mass email from Citizenship and Immigration Canada, forbidding them to discuss the funding cuts" (Voices, 2012, p. 1). Chart 6 shows the amount of funding the AAO was receiving and the amount, which was cut: 


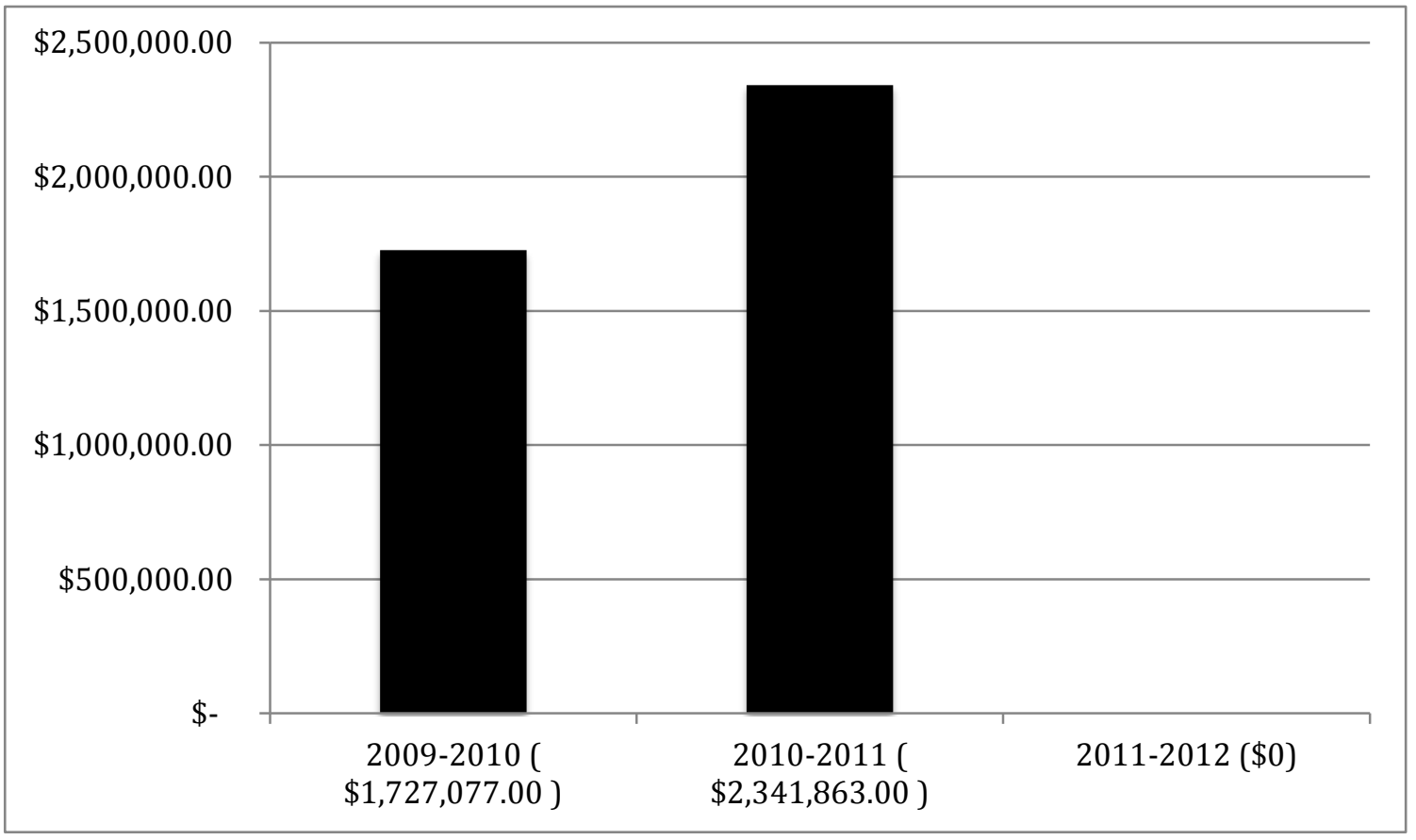

Chart 6. Summary of Federal Government Funding cut for the AAO (Funding Proposal, 2016)

By August 2011, the AAO also lost its funding from the province of Ontario, the City of Toronto, charity foundations, and private institutions. The AAO was no longer able to meet the deadline in the call for proposals and apply for funding because of a staff shortage. Currently, the only sources of funding for the AAO are the private donations provided by the Afghan community and the membership fees. The AAO has 1,670 members contributing $\$ 30$ yearly, which generates around $\$ 50,100.00$ annually. The combination of membership fees and charity private donations sum up to approximately $\$ 66,000.00$ to $70,000.00$ annually, covering the costs of the two full time employees, office rent, administration expenses, and provision of basic settlement services for newcomers (Funding Proposal, 2016, Report on Services, 2017). According to Feroz Hematyar, if an organization does not receive government funding in three constant years, then it becomes difficult to re-qualify for refunding. In addition, the Afghan community in Canada is politically underrepresented and has limited political 
connections to the federal government, in order to lobby and advocate for the Afghan ethno-specific ISSAs. Therefore, the AAO still remain unfunded (Report on Services, 2017). Chart 7 shows the variation of funding for the AAO before and after 2010 funding cuts.

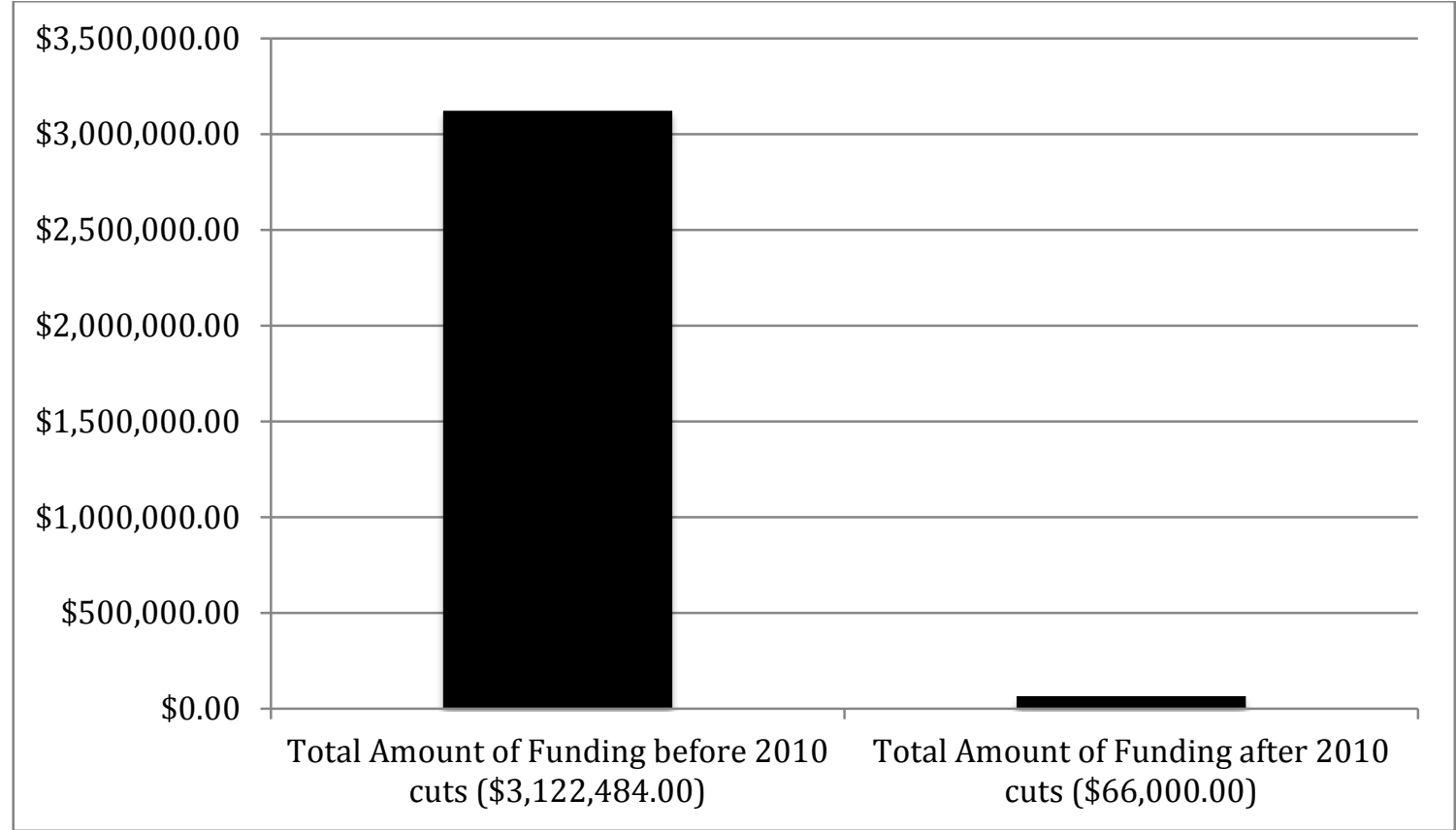

Chart 7. The Total Amount of Funding Before and After 2010 Cuts (Funding Proposal, 2016; Report on Services, 2017)

\section{Discussion}

This research shows that the federal government is the major funder of settlement services for newcomers. The AAO and the AWO relied on $90 \%$ of government funding to provide services. Therefore, any kind of cut could have a major impact on services. Importantly, the findings reveal that the AWO and AAO in Toronto region are affected the most by government funding cuts in 2010 , despite the fact that Toronto hosts the largest diaspora of Afghans in Canada with a majority of Afghan secondary migrants, who initially land in other cities, then move to Toronto to access services from the Afghan community. Nusrat's (2015) study also confirms this data and demonstrates that 
the accessibility of the AAO and AWO's services has become more and more limited in Toronto since 2010. Prior to 2010, 16 out of 17 participants were receiving services either from the AAO, AWO, or both. In contrast, 8 out of 17 participants received services from the AAO, AWO, or both, after 2010. Nine participants, who came to Canada after 2010, did not have access to these organizations' services.

Following the funding cuts, it was reported that the AAO closed down (Keung, 2010; Pagliaro and Mahoney, 2012). Our findings show that this organization still provides services on a small scale for clients, with limited financial support from the Afghan community. The community's support seems nevertheless conditional upon the AAO's services having a meaningful impact on the settlement and integration of Afghan newcomers. This fact reveals the importance of the AAO's services and the desperate need of Afghan newcomer community for the culturally and linguistically competent services. In this context, Song (2016) suggests the "group-differentiated rights" (p. 1), where services are provided based on recognition and understanding of newcomers' specific needs is extremely valuable for successful settlement outcomes.

Contrary to the government's policy, which anticipated that decreasing government funding would increase the private institutions' responsibility to meet the settlement needs of newcomers (Eakin, 2001; Shields et al., 2016), this study shows that the $\mathrm{AAO}$ lost its $25 \%$ funding from private institutions following the government funding cuts. This is because the AAO no longer has the government financial support required to afford having enough staff and programs to attract funds from the private sector, in particular administrative staff to apply for private funding and grants. In addition, the funding cuts, increased demands for services, and the lack of staff to provide services and 
meet the administrative burden, limit the capacity of the AWO to compete and apply for the majority of purchase of service agreements, matching contributions, and private institution funding sources. This policy "leaves affected and more financially vulnerable organizations scrambling to find an alternative funding base, often at the last minute" (Voices, 2012, p. 1). This shows that ISSAs need stable government funding to maintain their capacity for serving their clients, including their staff that play a vital role in attracting contract-based funding from alternative sources. Moreover, policy advocates argue that prohibition imposed on ISSAs by the previous Conservative government to discuss government funding cuts was "a direct violation of free speech rights under the Charter" (Voices, 2012, p. 1). Addressing these problems is important. As Taylor suggests, "transferring rights and resources (recognition) or not appropriately transferring rights and resources to a social group (misrecognition) impacts [social group's] wellbeing, wealth, citizenship and identity" (Faye, 2017, p. 68). According to Coulthard (2007) immigrants' successful settlement and integration are dependent on 'cultural recognition and institutional accommodation by the surrounding state" (p. 448). Further, it is argued that recognition and fair distribution of services by the government, taken together, would allow for the right kind of justice and integrative society (Iser, 2013, p. 1). This confirms that proper provision of resources by the government results in fostering better services, which in turn, leads to a better life and successful settlement and integration of newcomers.

\section{The Impacted Services of the AWO by Government Funding Cuts}

Before the government funding cuts, the AWO managed to serve settlement services for its clients with the funding provided by the federal government. However, 
due to the 2010 cuts, the AWO limited its services affecting the number of clients it served as shown in Chart 8:

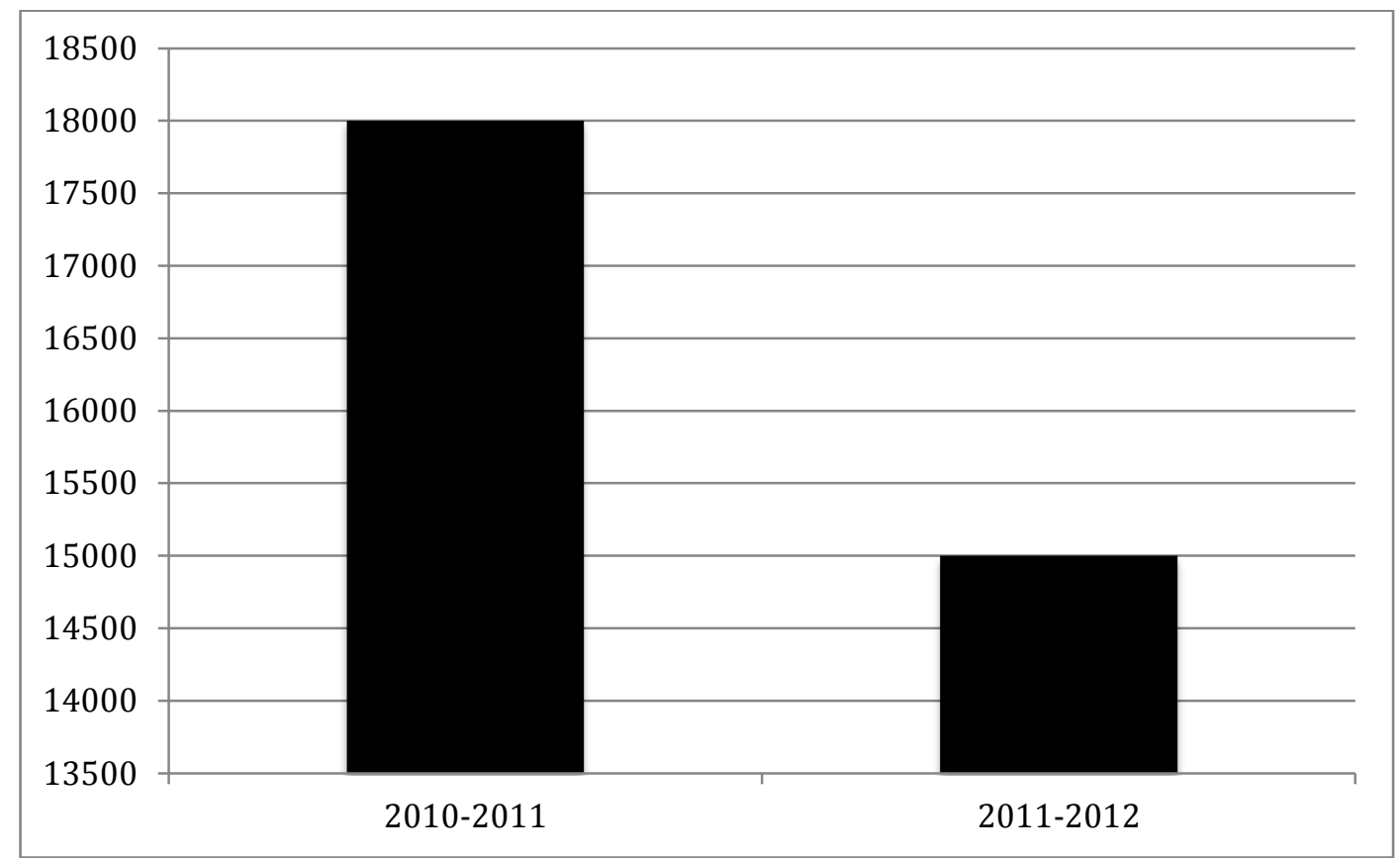

Chart 8. Number of Clients that the AWO Provided Settlement Services from 2010 to 2012 (Annual Report 2011; Annual Report, 2012)

The number of service users of the AWO decreased from 18,000 to 15,000 in one year. The provision of settlement services for Afghan newcomers was a shared responsibility between the AWO and the AAO. As the AAO lost all of its funding, terminating its services, its clients sought help from the AWO. As a result, the AWO faced "financial strain and increasing demand for services" (Annual Report, 2012, p. 2; Annual Report, 2013, p. 3). In addition, as a settlement service provider for refugees, the AWO also received 2,023 Syrian newcomer refugees, requiring settlement services, and further assisted, directly processed, and resettled 250 Syrian refugee cases (Funding Proposal, 2016; Report on "How Are We Doing?”, 2016). These situations, in the following years, increased the number of the AWO's clients, as shown in Chart 9, despite decreased funding. 


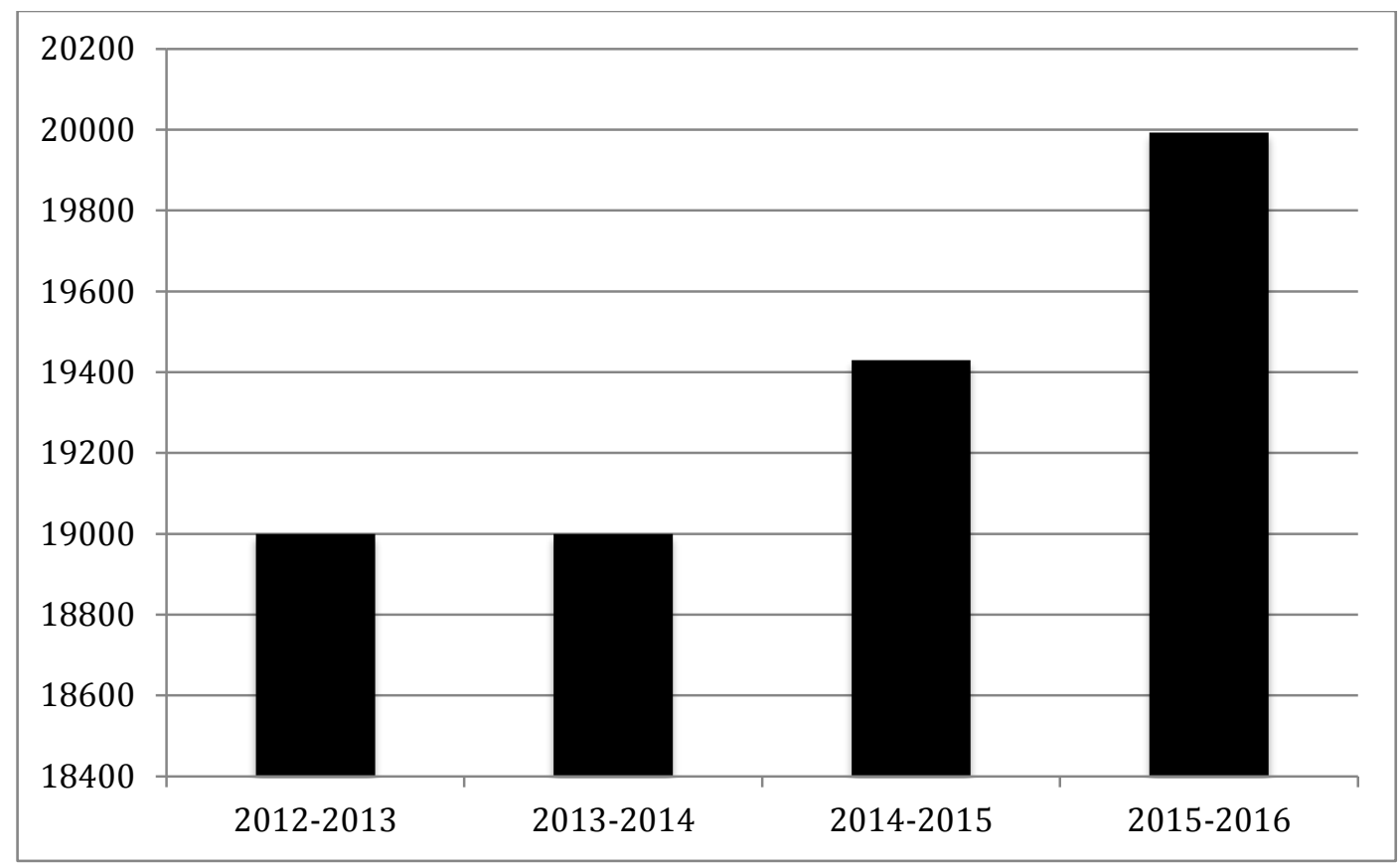

Chart 9. Number of Clients Provided Settlement Services by the AWO from 2012-2016 (Annual Report, 2013; Annual Report, 2014; Annual Report, 2015; Annual Report, 2016)

This contributed to longer wait times for accessing services of the AWO after 2010, indicated as one of the problems by 28 out of 34 participants in Nusrat's (2015) study. One of the participants shared her experience, saying:

When I landed in Canada I didn't know anyone and didn't speak a word of English. On my second day of arrival, I went to the AWO to seek help and that was my service shopping center where I accessed walk-in services almost every day for the first year to meet my needs. Now my cousin just arrived from Turkey, and in order to access the AWO services I have to book an appointment and wait to receive the services she needs, delaying her settlement (Nusrat, 2015).

The AWO's management decided to prioritize their services based on the newcomers' immediate needs and implemented cuts in other areas in order to manage the high volume of newcomer clients and deliver settlement services. For instance, the AWO downsized its location and moved to a smaller building in order to reduce rental costs. In addition, the AWO relied on 150 to 200 volunteers to assist in delivering settlement services annually (Annual Report, 2012). 
According to the AWO, their staff put their hearts and minds into the work to serve the higher number of clients with limited resources and funding. Over $98 \%$ of AWO's clients are coming from refugee backgrounds (Funding Proposal, 2015), and the majority of AWO's staff and board members, too, have personal experience of being refugees, thus having "firsthand understanding of the needs of clients" (Annual Report, 2010, p. 3). Therefore, in order to do their humanitarian work, the AWO staff does not turn away needy clients and serves as many newcomers as they are able, and "this is what makes [the AWO] unique and special"' (Annual Report, 2010, p. 3; Funding Proposal, 2016). Despite the high quality and quantity of the multiple services they deliver and the overtime hours they work, the AWO's staff have not received any salary raises in the past seven years. This issue requires recognition by providing sufficient funding and improving their working conditions. These findings and the ones that follows present the importance of the AWO's services and the way the AWO manages to serve its clients despite funding cuts. In the following section the most affected services of the AWO are discussed.

\section{THEME 1. Language Skills Development Programs}

\section{a. The Importance of Language Skills Development Programs for Afghan Newcomers}

The major settlement and integration challenge Afghan newcomers face in

Canada is the language barrier (Ludin, 2008; Nazar, 2012; Kohistani, 2012; Wali, 2012;

Ahmed, 2014). Three decades of war and forced migration have disrupted Afghans' education. Due to unstable refugee status and a lack of consistent access to education, in addition to English being a foreign language, Afghans often do not have formal education or literacy in their native languages nor English. Further, often, they do not have 
experience of co-gendered education, which contributes to their culture shock when exposed to the Canadian co-gendered education system, deterring their participation (Wali, 2012; Nazar, 2012).

The AWO offers 19 Language Instruction for Newcomers Classes (LINC) for newcomers at different levels of proficiency; which assists newcomers to gain English language skills necessary for effective settlement and integration. The classes provide "basic communication and life skills that are crucial for individuals to develop into capable, independent and active members in their new communities" (Annual Report, 2010, p. 5). The all-women language classes of the ethno-specific ISSAs, facilitated by Dari and Pashtu speaking facilitators, encourage Afghan newcomer participation. The gradual merging of gender-specific classes and including diverse instructor and facilitator help newcomers with their gradual and steadier adaptation to the new culture. This transitional program is essential for Afghan newcomers' integration in Canada (Nusrat, 2015).

Ibrahimi's (2014) research shows that Afghans in Toronto perform better in the English language than Afghans in Montreal, Vancouver, and Calgary. Ibrahimi reveals that the majority of Afghan participants from Toronto declared that the reasons they acquired English language and participated in language classes were the Dari and Pashtu speaking workers and facilitators of the AWO, who explained the importance of language classes for them. In contrast, a very limited number of Afghan participants in the three other cities indicated that they received language classes, contributing to their slower resettlement and integration.

A service user of AWO, Najib, shares his experience that "when setting priorities, 
the AWO helped me to prioritize language classes, which otherwise I would not know to do. I joined full-time language classes, which provided me with preliminary English knowledge, further leading to the school, college, a better career, and a stable life" (Nusrat, 2015, p. 4). Research finds that due to the lack of prior knowledge about Canada, it is challenging for Afghan newcomers to prioritize their settlement needs. Furthermore, because of language barriers, Afghan newcomers often are unable to understand when an explanation of need and service prioritization is provided in English (Ibrahimi, 2015).

The AAO helped 2,570 Afghan newcomers to successfully graduate from its English language classes (Funding Proposal, 2016). In addition, the AWO provides language training for over 700 newcomers annually. Therefore, the two ethno-specific Afghan organizations were more successful than other organizations in improving Afghan newcomers' language skills (Ibrahimi, 2015), leading to their successful social and economic integration and contribution to the host society.

\section{b. The Impact of Government Funding Cuts on Language Skills Development Programs}

When language classes of the AAO terminated in 2010 (Report on Services, 2017), the majority of students enrolled in the AWO LINC classes. Thus considerably increasing the number of LINC students for the AWO as shown in Chart 10: 


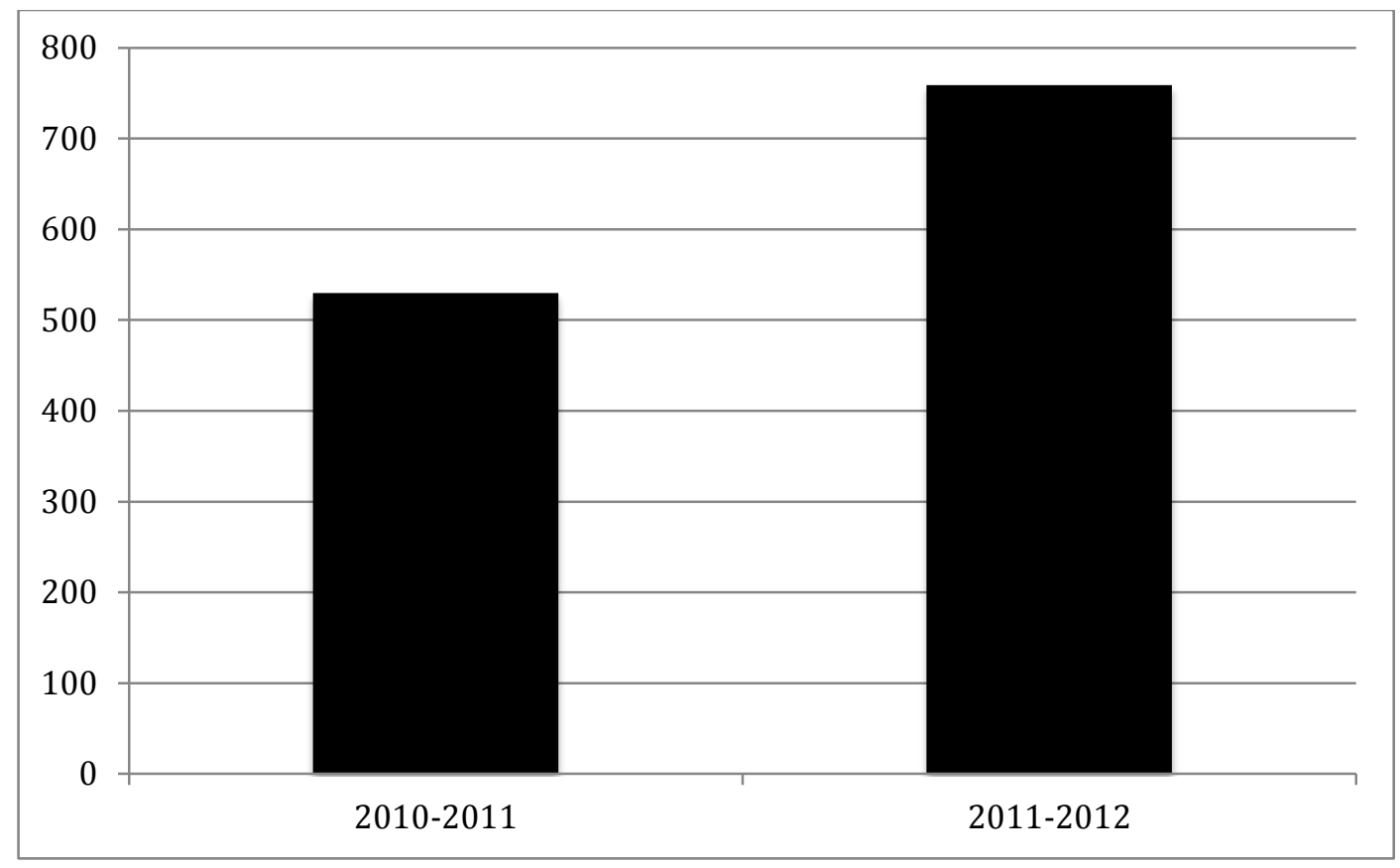

Chart 10. Number of LINC Students at AWO from 2010-2012 (Annual Report 2011; Annual Report 2012)

As the AWO had insufficient funds to provide LINC classes for an increased number of students, the organization increased periods of summer and winter breaks to six weeks for LINC students and staff to meet and serve the high demand of students for LINC classes (Report on Services, 2017). The AWO had no choice other than developing strategies to serve the higher number of needy clients with decreased and limited funding for language and skill development programs. The recent 2015-2016 Annual Report shows that the number of students remained as high as 703 students, over the past year with, however, no funding increment.

\section{c. Discussion}

Findings of this research assert that the most effective way for language skills development of Afghan newcomers is the English classes offered by the Afghan ethnospecific organizations. The government funding should therefore increase, not be cut. Funding cutbacks limit Afghan newcomers' access to classes and deter more than 500 to 
600 Afghan students from learning the English language annually. In addition, the extended longer breaks create a gap, which affects students as they often forget what they have already learned and the irregularity of classes deter their interest and participation.

Recognition theorists believe that in a socially just society, equality is maintained when minority groups' needs are not overlooked by the provision of services, based on the mainstream groups' needs (Honneth, 1995; Taylor, 1994; Arfken, 2013; Coulthard, 2007). This research suggests that the government funding cut policy was based on the assumption that all immigrants can access the mainstream ISSAs' services, discounting the fact that some newcomers need specific services provided by the ethno-specific ISSAs facilitating their adjustment to Canada, such as the all-women language classes for Afghan newcomers. In addition, service users indicate that due to the language barrier, the newcomer Afghans are often not able to receive services from other ISSAs, and even if they access the services they have to wait a long time until the organization provides an interpreter. Recognition theorists find that language is "at the heart of many claims for cultural accommodation by immigrants" (Song, 2016, p.1). Newcomers expect the government and society as a whole to recognize and accommodate their language needs at least in the first few years of their migration. Misrecognition of this fact, in a multicultural society, leads newcomers to "find it much harder to embrace themselves and their projects as valuable" (Iser, 2013, p. 1); therefore, impeding their settlement and integration. Landesman (1994) suggest that besides assuring equal recognition by "an identical basket of rights and immunities" (p. 38) for all, equal recognition requires special rights and entitlements for individual groups based on their needs. 


\section{THEME 2. Labour Market Participation}

\section{a. The Importance of Labuor Market Participation Programs for Afghan Newcomers}

Since 1990 the employment services offered by the AWO have been helping newcomers with their "long- and short-term career goals and support them through the initial job preparation process into a life-long process of skill-building, career development, and employment" (Annual Report, 2015, p. 8). The AWO plays a significant role in economic integration of Afghan newcomers through providing employment services to help both the low skilled newcomers with lack of language proficiency and high skilled Afghan migrants to obtain an employment.

The AWO provides a combination of skill and language trainings based on abilities of Afghan newcomers and the Canadian job market needs, leading to newcomers' employment. For instance, employment workers realized that many Afghan women, deprived of formal education, have sewing, crochet, and catering skills. Therefore, they organized the AWO's skill trainings according to these skills to make the newcomer Afghan women employable. These programs help Afghan women to develop their sewing, business, accounting, and English language skills in order to effectively join the Canadian job market (Annual Reports, 2010; Annual Report, 2013; Annual Report 2015). This has led many Afghan women to open their private tailoring businesses or secure employment as tailors at various companies such as the Canada Goose. For instance, Ms. Qadiri, a UNHCR sponsored Afghan refugee who did not speak a word of English upon her arrival from Moscow, upgraded her sewing skills and improved her English conversational skills at the AWO. As a result, she secured an employment, as a 
sewing machine operator, at the Canada Goose. Further, through her network, she initiated sewing job opportunities to more than 75 Afghan women (UNHCR, 2014).

Within two years, the skill training employment project of the AWO "empowers marginalized women through the formation of a business... that helps them contribute to the family income" (Annual Report, 2013, p. 3; p.15). Ms. Wedad is another refugee who benefited from skill training of the AWO. Through the help of the AWO's employment services she started leading crochet classes and organizing community Bazaar to promote crochet work and generate income for people's handicrafts. Currently, she runs her own small home-based business in Canada, receiving a good amount of crochet orders (Annual Report, 2015).

The AWO also helps in training newcomers for catering and food services sector. The Afghan Women Catering Group was trained and developed by the AWO, which presently operates as an independent business providing catering services throughout GTA (Afghan Women Catering Group, 2017). Many Afghan newcomers, who were supported through the employment services of the AWO, run restaurants or work in the food services sector. According to the social characteristics of Afghans in Census Canada, the majority of Afghans work for the food services industry (Pashtoonyar, 2011), a sector with a higher demand of employees in Canada (Department of Employment and Social Development Canada, 2016; Keung, 2016).

The employment services of the AWO also run the Foreign Trained Medical Practitioners' Focus Group. This highly specialized service is only offered by the AWO (Annual Report, 2010). This program has led many Afghan newcomer high skilled doctors, mental health counselors, and medical professionals, who completed their 
degrees in Afghanistan, to become practitioners in Canada. They otherwise would not be able to achieve their goals due to lack of support and guidance (Ibrahimi, 2015).

The AWO employment services develop these programs to help Afghan newcomers with employment and successful economic integration, preventing them from depending on social and welfare services in Canada. The labour market participation programs of the AWO have served about 200 clients annually, assisting $30 \%$ of their participants in securing employment (Annual Report, 2013). These linguistic competent skills based employment programs are not provided by any other settlement and employment services for Afghan newcomers in Canada (Nusrat, 2015), making the AWO employment services a vital need for them.

\section{b. The Impact of Government Funding Cuts on Labour Market Participation Programs}

Due to the federal government funding cutbacks in 2010, the AWO had to lay off a full-time employment worker and an employment counselor, who played a significant role in developing and facilitating employment programs (Report on Services, 2017). This left the AWO with only one employment worker serving an increased number of clients. With one worker being able to serve a limited number of clients, the skill training programs were also scaled back. This impacted the quantity and quality of services the AWO previously provided. Other agencies employment services remain ineffective for the majority of Afghan newcomers, as they lack skill training programs adapted to their clients' needs and skills. Therefore, the Afghan newcomers typically remain un-served. The AWO's executive director, Adeena Niazi, mentions that hiring employment workers and job developers are an immediate need of the AWO, in order to serve the large number of Afghan newcomer clients in both Peel and Toronto Regions (Report on 
Services, 2017).

\section{c. Discussion}

The literature, findings, and the services users' responses confirm that the Afghan ethno-specific organizations have been successful in their offering of employment services producing better results than other organizations. These organizations are best placed to understand their clients' immigration experiences, through their knowledge of Afghans' occupational skills and already established professional networks. In fact, these organizations are able to find Afghan newcomers employment opportunities easier and faster.

According to Nusrat's (2015) data, before the 2010 funding cuts, the majority of newcomer service-user participants credited the AAO and AWO for helping them with securing employment. The impact of insufficient fund for labour market participation programs for the AAO and AWO is significant as the majority of Afghan newcomer participants declared that they struggled to find employment after 2010.

When the government requires reports from ISSAs, it considers the number of clients the organizations served, overlooking the impact of services the organization provided for newcomers. This policy impacts the ethno-specific ISSAs the most, leading to funding cuts. Ethno-specific ISSAs serve less clients in numbers than the mainstream ISSAs. However, they tend to be more successful in the settlement and integration of newcomers than the mainstream ISSAs. An example of this is the employment programs of the AWO. This is an important discovery because re-funding first requires understanding and recognition of impacts. Funding these services itself is an act of recognition, and the provision of these support services provides "the concerned groups 
with the power 'to be well', and the power 'to influence"' (Faye, 2017, p. 68), and the ability to economically contribute to the society.

\section{THEME 3. Support Services}

\section{a. The Importance of Support Service for Afghan Newcomers}

According to Kohistani (2012) Afghans represent one of the largest refugee group (23\% of refugees) in Canada (p. 7). Therefore, Afghan newcomers often experienced premigration war, persecution, and/or trauma, which impact their mental health in Canada (Sidiqi, 2012). Moreover, the lack of language and culturally competent counseling services for Afghan newcomers "negatively affect their mental wellbeing (p. 28). One of the Afghan newcomer women in Sidiqi's (2012) study mentions the importance of counseling services provided by Afghans:

I feel that the problems Afghans experience can only be best understood by Afghans. Many Afghans suffer from psychological problems due to their horrific experiences during the war, the struggles to make a living in Canada and lack of assimilation into the Canadian society. I truly believe that these experiences and struggles could not be comprehensible to a non-Afghan health professional. The non-Afghan professionals hear stories as stories and help to the extent they can. I am not saying that everyone should seek help from people of their own ethnicity but sensitive experiences of Afghans and many other refugees can be best understood by people who have also experienced these events and are sensitive to the cultural protocols that come along with such experiences (p. 39).

Sidiqi (2012) concludes that Afghan newcomers need formal guidance and counseling services in their native languages provided by their community organizations, in the earliest stages of their post-migration. Several studies support her findings, that refugees who do not have access to pre-existing ethnic communities and support systems are at a risk for mental health problems (Beiser, 2009; Noh \& Kaspar, 2003; Simich, 2003).

Kohistani (2012) finds that “Afghans' central source of support is family, then friends and community members" (p. 20). His study confirms that Afghans' mental well- 
being, successful adaptation, settlement and integration in the host county rely on culturally competent or adapted settlement and counseling services provided by the Afghan community organizations, such as the AWO. One of the male participants in Kohistani's study mentions, "if you go to the Afghan community even if they can't help, they are compassionate and that makes you feel better. I feel I can talk to them openly and share my secrets" (p. 19). Ibrahimi’s (2014) data reveals that the majority of participants in Toronto, mentioned the AWO as a social support center where their needs are met and problems are solved. In contrast, Afghan participants of his study in Montreal, Calgary, and Vancouver responded that they lacked competent cultural and linguistic social and emotional support services, contributing to their isolation, slower settlement and integration process. This data demonstrates that the AWO's counseling services is a safe space for Afghans to openly and honestly share their needs and receive services accordingly.

The AWO provides one-on-one counseling services and group programs such as Wellness Program, Women Circle, and Wellness Café (Annual Reports 2011; Annual Report, 2016). In one-on-one sessions, both male and female clients are assessed and provided with guidance, support services information, mediation, shelter, and financial help (Funding Proposal, 2016).

The AWO has also been successful in dealing with domestic violence cases. Ahmed's (2012) study asserts that "violence against Afghan immigrant women in Canada does exist" (p. 2). She further argues that Afghan women, who are victims of intimate partner violence, are less likely to use formal services due to fear of institutional intervention and cultural barriers such as shame, fear or retaliation, separation from 
children and more. The group counseling programs of the AWO aim at helping and encouraging Afghan women to share their stories, struggles, and problems in a safe environment without fear of being judged, leading to accessing services and wellbeing of the majority of these women (Annual Report, 2016). Based on AWO's extensive knowledge of Afghan women's needs, the group programs are organized as a "culturallyappropriate model to establish a starting point for women's self-help and advocacy" (Annual Report, 2011, p. 13). Further these programs "increase awareness about mental health issues, decrease stigma towards mental illness and foster help-seeking behavior in newcomer communities" (Annual Report, 2016, p. 9). It is easier for Afghan women to trust and access serveries from ethno-specific Afghan organizations rather than other multicultural settlement organizations (Ahmed, 2012). Nusrat's (2015) research refers to a counseling service user of the AWO who shared her thoughts:

I fear accessing other organizations' services when I face family issues because they often cannot understand the level of complexity. However, when I refer to the AWO and I am assisted by an Afghan worker in a one on one session, they easily understand the situation and guide me as to whether I need mediation or separation.

Ahmed's (2012) study further finds that the AWO is "the only organization in Ontario funded by the Citizenship and Immigration Canada, and specific to Afghan women. There are no other Afghan associations with similar missions and goals readily available for such women" (p. 50), confirming the importance of the AWO counseling services for Afghan women facing domestic violence. For instance, the AWO mentions the case of Samara who is one of the many women who is helped by the AWO counseling team. She sought help from the AWO after enduring years of domestic violence, physical, emotional and financial abuse from her husband. She was provided 
immediate help ensuring her and her two children's safety. The AWO's counseling services raised Samara's confidence and assisted her in finding employment and admission to a university. She successfully completed her Bachelor's and Master's degrees from the University of Toronto, while receiving social and emotional support from the AWO. She currently works at the RBC Capital Markets, and she "credits her AWO counselor, Fauzia Khan, with giving her the hope, courage and motivation to go on” (Annual Report, 2016, p. 13). Samara voluntarily provides support to other newcomer women at AWO, in order to give back to this organization for the support she has received (Annual Report, 2016). The literature reviewed asserts that the counseling services of the AWO help Afghan newcomers with their mental well-being and social participation and contribution while settling and integrating into Canada.

\section{b. The Impact of Government Funding Cuts on Support Services}

At the AWO one-on-one and group session counseling and support was initially available on a daily basis. However, currently due to the funding cuts and increased number of clients, this service is provided by one part-time counselor and it is only available based on appointments on specific days of the week (Report on Services, 2017). The limited amount of funding made it unaffordable for the AWO to hire full-time Afghan professionals to provide counseling. It is noteworthy that this service mostly relies on professional volunteers' support. Although volunteers provide precious support, their work should be coordinated and supervised. This has become an extra responsibility for counselor and settlement workers: due to the funding cutbacks, the AWO no longer has a volunteer coordinator to coordinate volunteers to meet clients' needs. This has left many Afghan newcomer refugees and women with lack of social and emotional support, 
affecting their effective settlement and integration. According to Niazi, the AWO is in desperate need for support services funding to hire linguistic and culturally competent Afghan specialized counselors as well as a volunteer coordinator to deliver services efficiently (Report on Services, 2017).

\section{c. Discussion}

This research finds that the lack of funding for culturally and linguistically competent support services, including counseling, can have severe impacts on Afghan newcomers. According to the UN-Women Afghanistan Report (2017), "87 per cent of women in Afghanistan experience physical, sexual or psychological violence during their lifetime, with 62 per cent experiencing multiple forms" (p. 1). Furthermore, according to the World Health Organization (2015), 16.5\% of Afghans suffer from mental health problems, particularly post-traumatic stress disorders. Therefore, when refugees with such backgrounds come to Canada, funding and the provision of effective support services are essential in order to ensure their mental and physical well-being, and successful settlement and integration. The literature demonstrates that the government has implemented funding cuts anticipating that volunteers can provide these services. However, research highly recommends that such professional services for a vulnerable population should be provided by specialized, experienced and knowledgeable permanent staff (Hugman, 2004). Understanding and recognizing newcomers' pre-arrival conditions and lifestyles are important to provide services accordingly.

The Shafia family's murder case is an incident resulting from the inaccessibility of linguistic and culturally competent settlement and support services for Afghans. In 2009, Mohammad Shafia, who moved to Montreal from Afghanistan in 2007, committed 
an honour killing of his three daughters and his wife. Due to the of lack cultural and linguistic transition programs and settlement services for Afghans in Montreal, the family struggled to successfully adjust and settle into the Canadian society and culture. For two years they sought help from mainstream support services, but due to lack of mutual linguistic and cultural communication and understanding, the services failed to assess and respond to their needs, leading to the brutal incident (Findlay, 2012). The support programs of the AAO and the AWO, in particular AWO's support services for Afghan women, play a major role in settlement and integration of Afghans, helping to prevent the occurrence of such incidents. In Afghanistan "women who seek help to escape violence often face indifference or criminal sanctions for committing moral crimes" (UN Women, 2017, p. 1). Afghan women often come to Canada with the same fear; therefore, the AWO provides them with awareness and a safe and trustworthy space to access appropriate services. Thus, this research suggests that the continuous and enhanced provision of support services by specialized staff through ethno-specific ISSAs, particularly by the AWO, is vital for Afghan newcomers and their successful integration into Canadian society.

\section{The Impacted Services of the AAO by Government Funding Cuts}

As the funding cuts were implemented, all the federal government funded programs of the AAO were terminated. The AAO had to lay off $80 \%$, or 25 , of its fulltime employees. (Funding Proposal, 2016; Voices, 2012). In addition, the AAO was no longer financially able to pay the mortgage of the property it bought in 1990, where it had sufficient space to serve its large number of clients. Therefore, funding cuts left the AAO with a debt of over $\$ 300,000.00$ (Annual Report, 2010; Voice, 2012). In 2012, the AAO 
had to sell its property to pay the debt, and moved to a small rental, a two-room office space, in a location close to its clients' catchment area (Report on Services, 2017).

The AAO use to serve over 4,000 clients annually (Annual Report, 2010). Since 2013, around 9,000 to 10,000 clients have been seeking the services of the AAO annually. As a culturally and linguist competent organization AAO often remains the first source of service provider contact for Afghan newcomers in Canada. However, due to government funding cuts for formal settlement services, the AAO is able to provide clients only with basic informal services, including counseling, immediate settlement, and referral services to a limited number of clients as shown in Chart 11:

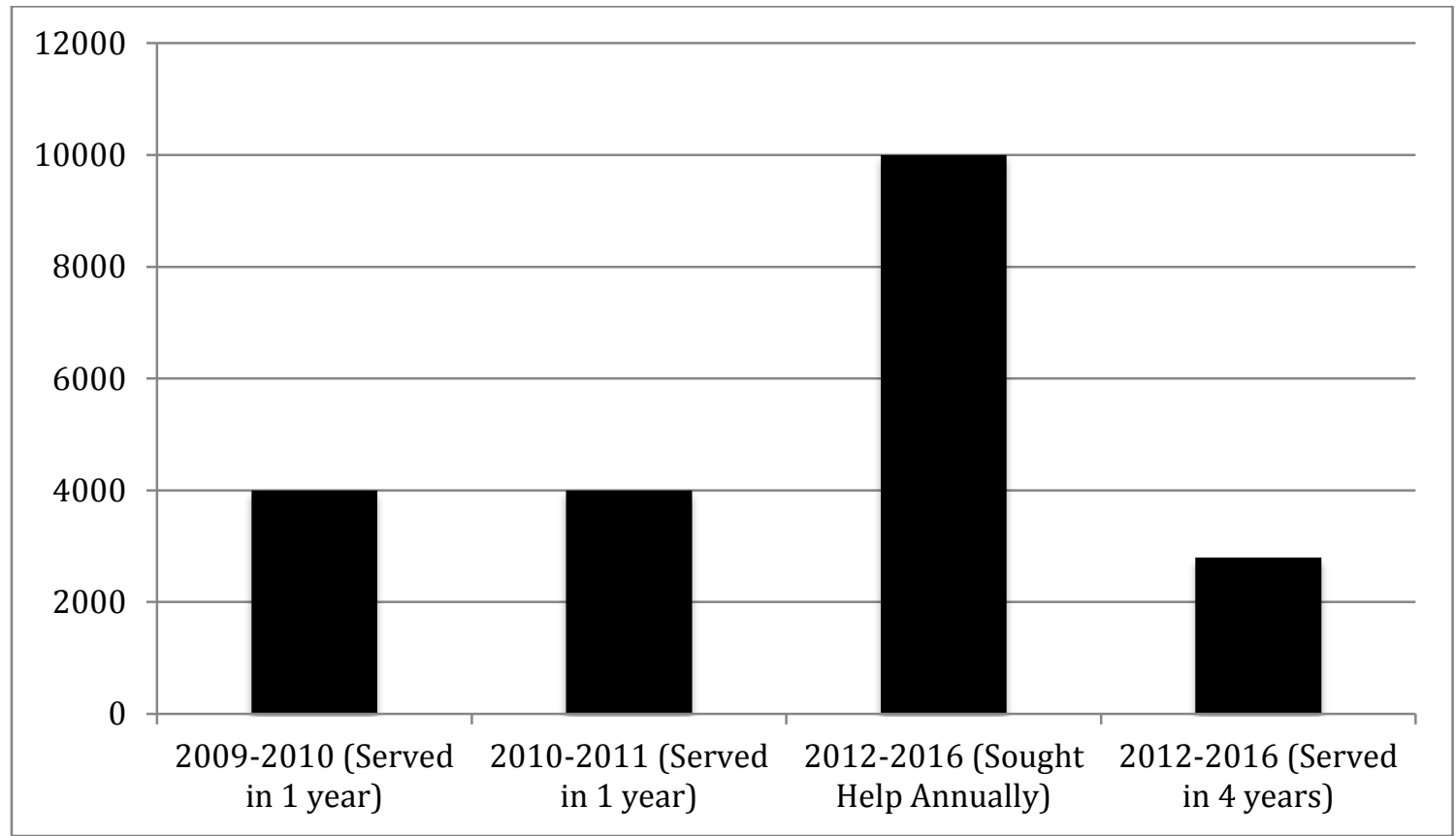

Chart 11. The Number of clients served by the AAO (Annual Report, 2010; Funding Proposal, 2016; Report on Services, 2017).

In the past four years, despite the increased number of clients in need of services, the AAO served half of the clients it previously served annually. This is clearly not sufficient to meet the high demand of Afghans for ethno-specific settlement services. The majority of the AAO's basic services are provided by 60 to 100 volunteers annually (Funding 
Proposal, 2016; Report on Services, 2017).

\section{THEME 1. The Refugee Assistance Program}

\section{a. The Importance of Refugee Assistance Program for Afghan Newcomers}

According to the UNHCR (2017), Afghanistan remained the second-largest

refugee source country. Many of these refugees are temporarily settled in neighboring countries to Afghanistan, and they are in desperate need of resettlement for prolonged protection. The AAO and AWO, as private refugee sponsorship agreement holders, are the two organizations providing resettlement for these refugees. In addition, the AAO and the AWO help Afghan Canadians to reunite with their family members from Afghanistan through this program (Annual Report, 2010). The majority of Afghans come to Canada through the immediate family sponsorship and the private refugee sponsorship. Afghans often do not meet the financial and eligibility requirements of other Canadian immigration classes to come to Canada (Mohsini, 2016). Therefore, these remain the only ways for Afghan Canadians, in particular refugees, to reunite with their family members in Canada, making the refugee sponsorship and assistance programs of the AAO and AWO very important services for Afghans. In the last 31 years the AAO has sponsored more than 16,000 Afghan refugees (Funding Proposal, 2016). About $90 \%$ of Afghans are sponsored by the AAO in Ontario (Report on Services, 2017). Until 2010, the AAO was the second highest refugee sponsorship organization in Ontario (Report on Services, 2017).

Furthermore, once these refugees arrive in Canada, the AAO and AWO provide the initial settlement support. The AAO and AWO have successfully provided refugee resettlement assistance for 75\% of Afghan refugees in Ontario (AAO Report on Services, 
2017). Hematyar finds that "the cultural differences between the two countries along with the difference in language are the greatest barriers [Afghan newcomer refugees] face when they become a part of the Canadian society" (Final Report, 2016, p. 3). Therefore, the AAO has been playing a significant role as a cultural and linguistic interpreter and mediator for Afghan newcomer refugees, providing transitional assistance and limiting their culture shock experience (Ibrahimi, 2015).

Afghan refugees have often come from refugee camps, where they have limited or no access to services, contributing to their lack of knowledge about most of the services available in Canada. Therefore, the AAO and AWO provide them with mentoring, monitoring and consulting service, which familiarize them with the Canadian system and society. These services include: pick up from airport and immediate accommodation; assistance with housing, household items, school admission, shopping, employment, language classes, banking, health services, public transportation, telephone services; and filling and filing applications for Ontario Health Insurance Plan, Social Insurance Number, and Permanent Residency card (AAO Annual Report, 2010, Ludin, 2008). The $\mathrm{AAO}$ use to be the only organization providing refugee settlement services through its multiple satellite offices close to Afghan newcomer refugees' communities (Funding Proposal, 2010). It was a one-stop community service provider for these refugees (Annual Report, 2010). These settlement services of the AAO helped Afghan refugees to "participate to the best of their ability in the Canadian economy and society as quickly as possible" (Funding Proposal, 2016, p. 2), contributing to Afghan newcomers' selfsufficiency and future success in Canada. 


\section{b. The Impact of Government Funding Cuts on Refugee Assistance Programs}

The RAP was the main source of funding for the AAO to provide immediate linguistic and culturally competent settlement services for Afghan refugees upon their arrival. However, due to the 2010 funding cutbacks the AAO's formal settlement services stopped. The AAO is still a sponsorship agreement holder organization, and, despite its scarce resources, it has sponsored 515 refugee cases since 2010 as shown in Table 12:

\begin{tabular}{|l|l|}
\hline Year & Sponsored \& Processed \\
\hline $2010-2011$ & 222 Cases \\
\hline $2012-2013$ & 117 Cases \\
\hline $2014-2015$ & 176 Cases \\
\hline Total & 515 \\
\hline
\end{tabular}

Table 12. Number of the AAO' Sponsored Cases Since 2010 (Funding Proposal, 2016)

After the RAP funding ended, the AAO had no source of funding to provide refugee resettlement assistance for these refugees in order to facilitate their adaptation, settlement, and integration process. The executive director of the AAO notes, "we strongly believe at least 5 years, culturally and linguistic sensitive, mentoring/monitoring and consulting service is required for any family starting life here to find the proper way of adjusting to the society" (Funding Proposal, 2016). This situation highlights the urgent need for the government to restart the AAO's RAP funding.

\section{c. Discussion}

An important result of this research, which has been overlooked by the government in its decision to cut funding for ethno-specific Afghan organizations, is that unlike economic and voluntary migrants, Afghans are forced migrants, who are spending years vulnerably in exile before they settle permanently in Canada. Therefore, cutting the RAP funding for initial service providers for Afghan refugees contributes to their continued vulnerability, leaving some of their most urgent needs, such as physical and 
mental health support, not adequately met. This inevitably impedes successful settlement and integration of many Afghan newcomers.

In comparison to most refugee populations, Afghans have proven to be successful in terms of social, cultural, and economic settlement and integration in Ontario (Census Canada, 2011). Credit goes to the government of Canada for previously funding essential services and the ethno-specific ISSAs for providing these services to support the Afghan newcomer population. Before funding cuts for ethno-specific ISSAs the recognition of pre-arrival identities, background, conditions, and abilities of service users of ISSAs are important and need to be taken into consideration in order to shape services accordingly and prevent their misrecognition and marginalization in the host society (Gokserl, 2014; Coulthard, 2007). Thus, this research suggests that the absence of these ethno-specific services will place Afghan newcomers in more vulnerable conditions and unsteady settlement and integration processes.

\section{THEME 2. Information, Orientation, and Advocacy Programs}

\section{a. The Importance of Information, Orientation, and Advocacy Programs for Afghan Refugees}

The AAO has provided "effective advocacy to Afghan Canadians and others in matter [sic] affecting their rights and status in Canada" (Annual Report, 2010, p. 3). The organization acted as a bridge between the Afghan newcomers, the Canadian institutions, and the Afghan governmental organizations to solve various issues faced by this population. When Afghans started migrating to Canada, the Canadian credential assessment institutions were not familiar with the education system of Afghanistan; therefore, they did not accept Afghan documentations for evaluation. This impacted Afghans in effectively using their human capital in Canada. The AAO was the only 
organization that advocated for Afghan newcomers, negotiated, and convinced the Comparative Education Services at The University of Toronto, International Credentials Assessment Services, and World Education Services to evaluate Afghans' educational credentials (Nusrat, 2015). The AAO also offered to provide official and trustworthy document translation for credential evaluation. This benefited many educated Afghans to either upgrade or use their education in Canada, leading to employment opportunities in their field of interest (Report on Services, 2017). These facilities assisted speedier economic integration of skilled Afghan newcomers.

The AAO's official notary stamp was also recognized as a credible source for authorization of Afghan newcomers' birth certificates, immigration documentations, marriage certificates, educational and business documents, and other documentations. This facilitated Afghan newcomers' legal integration and their eligibility to receive public services.

As early as 1985, the AAO also launched its first community newspaper, Neda-eMahajeer (Refugees Voices), Afghan radio program, Afghan Canadian TV program, and a multilingual website, providing advocacy, orientation and settlement services, awareness about Canadian culture, and information on accessing services (Annual Report, 2010). Many Afghan newcomers across the country were informed about events in Canada and internationally, the Canadian immigration laws and policies, and settlement services. A participant from Nusrat's (2015) study confirms the importance of these services saying:

I live in Whitby, and when I needed a service or had a question regarding settlement services, I used to ask and get a response from at least one of the AAO media sources, which was very convenient. If I faced a problem, they would advocate for me through their media (p. 20). 
The AAO developed these media tools to provide indirect settlement services, successfully meeting the short-term and long-term settlement needs of Afghan newcomers in Canada.

\section{b. The Impact of Funding Cuts on Information, Orientation, and Advocacy Programs}

Due to the 2010 government funding cuts for information, orientation, and advocacy programs, the AAO could not afford to provide these services, resulting in their termination and silencing Afghan newcomers' voices (Report on Services, 2017). Since these advocacy services of the AAO terminated, the credential evaluations for Afghan documents have also stopped by the Canadian credential assessment centers. This has prevented many educated Afghan newcomer professionals from using their human capital to successfully settle and integrate into Canadian society. It has further contributed to their dependency on social and welfare assistance. Moreover, since the majority of Afghan newcomers across Canada accessed settlement services through the media tools provided by the AAO, their termination has left Afghans with no linguistically competent and easily accessible services.

\section{c. Discussion}

This research finds that beyond provision of settlement services, the AAO perceives itself as the entity that is mainly responsible for the Afghan community in Canada, providing a voice to various needs of Afghan Canadians. In addition, the media tools of the AAO expanded its ability to provide services beyond its boundaries in Ontario and across the country for Afghan newcomers. When Afghans could not voice their needs due to a language barrier, it was the AAO that advocated for them, even if 
these people did not live in the Ontario region. The funding cuts that limited the media tools provided by the AAO had a negative impact not only on Afghan Canadians in the Ontario Region, but also on the Afghan Canadians living in the entire country. The government favored to allocate more funding to the provision of direct settlement services by mainstream ISSAs, eliminating and limiting funding for indirect settlement services of ethno-specific ISSAs. This policy has disregarded the fact that for many newcomers, like Afghans, the provision of linguistically competent, indirect settlement services is more essential and efficient than the direct services of the mainstream ISSAs, which they have trouble accessing due to a language and cultural barriers.

The ethno-specific ISSAs advocate for newcomers, negotiate mutual recognition between the newcomers and host society, and promote marginalized newcomers' public recognition. Taylor believes that marginalized individuals are capable of creating value,

policy, and meaning. These meanings and policies are best presented by the individual's cultural and ethno-specific community as a group, leading to effective outcomes (Rodrigues, 2017). Findings of this research reveal that de-funding the services, such as information, orientation, and advocacy, provided by ethno-specific ISSAs further marginalizes Afghan newcomers by muting their voices and limiting services based on their needs.

\section{THEME 3. Community Connection and Youth Program}

\section{a. The Importance of Youth Programs for Afghan Newcomers}

In the first and second decade of Afghan migration to Canada, the Afghan ethnospecific ISSAs were focusing more on settlement of the first generation adult immigrants, expecting the second generation and youth to easily integrate and adapt to the Canadian 
society (Nusrat, 2015). However, Afghan newcomer families' challenges such as language and culture barriers impact the settlement of youth and the second generation of Afghan immigrants (Nazar, 2012). Language and culture become barriers between parents and their children and the Canadian school system (Amir, 2009, Bedri, 2009, Nazar, 2012). As a result, Afghan youths struggle to negotiate between the two cultures and encounter "numerous challenges in trying to integrate into the school system" (Nazar, 2012, p. 1), which contribute to high rates of early drop out and later affect their entry into secondary institutions and the labour market, and access to recreation services (Amir, 2009). Therefore, stress and trauma experienced by Afghan youths lead to "unmet mental health needs among this group contributing to isolation, depression and an increase in the incidents of suicide" (Quirke, 2014, p. 10). In 2006 the Toronto District School Board Census (TDSB, 2006) has shown that Dari and Pashto-speaking students are one of the most at risk student populations - those who are more likely to drop out of high school and less likely to apply to post-secondary education (Brown, 2009). In addition, demographically, the majority of Afghans living in Canada are young, around 50,040 individuals, who are under the age of 34 (Marchand et al., 2014). The AAO and AWO are the only organizations that consider these facts and therefore focus more on helping the Afghan newcomer youth and the second generation Afghans to successfully adapt and integrate into the Canadian Society.

The AAO and AWO develop various youth programs and they positively respond to these issues, as they are provided in both English and Afghan languages, and by people who are familiar with both cultures. This makes it easy for all parties, for instance, the youth, parents, and other institutions involved, to understand and negotiate the issues. 
These programs provide settlement, mentorship, civic engagement plans, and solutionfocused counseling. These services often serve at-risk youth by one on one counseling, referrals to lawyers, assistance with court and school issues, mediating conflicted situations, and aggression replacement training. These initiatives help youths to reduce their level of social isolation and assist their academic success and integration into the Canadian society (AAO Annual Report, 2010; AWO Annual Report, 2010).

Both organizations partnered with TDSB and worked closely to meet Afghan youths' needs. They further established homework clubs to support students to succeed academically in school. The AAO implemented the Reach Program, which provided personal tutoring for at-risk students of Afghan decent. 80 Afghan youths benefited from this program delivered by 48 tutors within a year (Annual Report, 2010). The AWO also partnered with the Afghan Association of York University and The Afghan Canadian Sports Association to pair up youth with university students and Afghan Youth Athletes, in order to be coached by experienced youths (Annual Report, 2012). In addition to the academic support, these mentors mediated and provided cultural interpretation between youths and their parents moving them towards a successful integration path. The AWO also established new programs to support youths such as: a series of twelve-week workshops, which enable youth to cope with obstacles they or their parents faced during migration to Canada (Annual Report, 2011). The Reunification and Adaptation Program was initiated by AWO to use peer support and mentorship strategies to bring parents together to better understand the needs of their children (Annual Report, 2013). The AWO also designed the Youth Opportunity Project to assist Afghan youth between ages of 18-24 and who were out of school due to multiple barriers to seek a career (Annual 
Report, 2014). The Afghan Youth Ambassadors and Playing with Rainbows were additional programs supporting social inclusion and integration of Afghan youths (Annual Repots, 2014).

In 2014, the AAO reported, "there has been an explosion of Afghan youths, and second generation Afghans, who are graduating from the post-secondary institutions and entering the professional work" (Moswer, 2014). Many of these professionals are doctors, engineers, police officers, community mobilizers, lawyers, entrepreneurs, and psychologists (Final Report, 2016). Afghan parents also reported positive impacts of these services to the AWO and AAO (AWO Annual Report, 2016; Final Report 2016). In addition, all 34 participants of Nusrat's (2015) study mentioned that they need more cultural and linguistic competent transition programs to help them and their children adapt to the Canadian lifestyle. They indicated that if they need counseling and consultation regarding family issues and parent and teen conflicted situations, and linguistic and cultural negotiation, they refer to the AAO and the AWO. One male participant, who came to Canada in 2013, explains why Afghans prefer these organizations (Nusrat, 2015):

When we face a family issue we go to either the AWO or AAO because they know both the left and the right, Afghan culture and Canadian culture. Therefore, they make judgments accordingly. I have had problems with my teenage son, due to my lack of understanding of the Canadian culture. When I went to his school counsellor, they were neither able to make sense of my thoughts, nor did I understand theirs. Later we went to the AAO and they mediated by explaining the cultural differences and helping us understand both sides, which solved the problem.

The AAO, for the first time, organized two workshops in 2015 and 2016 to evaluate, "appreciate and identify the achievements and success of the youths in AfghanCanadian society" (Final Report, 2016, p. 4). In these workshops, the AAO recognized 
individuals for their parenting roles, community engagement, and youth's academic achievements. Further, the AAO tried to bring together the new Afghan professionals to become mentors to the younger generation in order to become inspired and succeed throughout their social, cultural, and economic integration process. Literature shows that these programs, altogether, effectively help Afghan youth to succeed in Canada.

\section{b. The Impact of Government Funding Cuts on Community Connection and Youth Programs}

Although, the AAO provided essential services for the Afghan newcomer youth, the government funding cuts terminated its youth and Reach Programs. Since these programs had very positive concrete outcomes for this Afghan community, the community members financially supported the AAO to re-instate them. This enabled the AAO to continue providing youth services, however, in a very smaller scale due to the limited amount of funding provided by the members and private donations (Report on Services, 2017). For instance, out of 400 to 500 referred youths, the AAO is able to serve a maximum of 70 to 100 clients annually.

The AWO's programs are only available to a limited number of youths due to the reduced government funding for community connections and youth programs. In addition, as volunteers support many of these youth programs, the lack of a volunteer coordinator for the AWO remains a barrier in recruiting and coordinating them, in particular, the youth mentors (Report on Services, 2017).

\section{c. Discussion}

Findings of this research reveal Afghan newcomers' significant need for youth programs. The government focuses on allocating more funding for services assisting adult newcomers to settle and integrate into Canada, expecting schools and other 
institutions to meet the newcomer youth's needs. However, a study conducted by the Affiliation of Multicultural Societies and Services Agencies of BC (2016) states that the ethno-specific ISSAs are more successful in assisting newcomer youth than mainstream ISSAs and other institutions. In particular, ethno-specific ISSAs support identity development and help newcomer youth to overcome pre-migration trauma.

The AAO and AWO are first and foremost organizations responding to the needs of at-risk Afghan newcomer youths, leading to their successful settlement and integration. Khwaja (2016) credits the AAO's and AWO's services, and reports that youth with Afghan backgrounds have the lowest crime rate in Ontario, and, in 2015, the majority obtained post-secondary education. Despite the effective impacts of the AAO's and AWO's youth programs, the funding cuts leave the AWO as the only organization providing culturally and linguistically competent services for Afghan youth. More than half of the Afghan population in Canada are youth; in addition, the majority of Afghan newcomers are youth, requiring more funding for the provision of youth programs. The politics of recognition theorists believe that "the politics of recognition is grounded on judgments about what makes a good life—-judgments in which the integrity of cultures has an important place" (Song, 2016, p. 1, Coulthard, 2007); therefore, these theorists promote cultural accommodation and ethno-specific support services for newcomers in a new society. In this context, the ethno-specific organizations are more successful, and the combination of both cultures (Afghan and Canadian) "serve as 'contexts of choice,' which provide meaningful options and scripts with which people can frame, revise, and pursue their goals" (Song, 2016, p.1). Hence, Rodrigues (2017), suggests the recognition of an assistance measure, establishment of bicultural and bilingual ethno-specific ISSAs, 
"so that they can serve people from the minority as well the minority language group" (p. 1), leading to their successful settlement and integration.

\section{Conclusion}

In this research, it is argued that the ethno-specific ISSAs' cultural and linguistic competent services are successful in adaptation, settlement and integration of newcomers. The federal government of Canada is recognized for previously providing sufficient funding for these services, which contributed to Afghan newcomers' success. However, after 2010, the ethno-specific ISSAs have been experiencing drastic government funding cuts and continuous limitation of funding for settlement services. Therefore, this study, for the first time, demonstrated the impact of funding cuts on services and service users of ISSAs through in-depth analysis of two case studies of Afghan ethno-specific organizations, the AAO and the AWO. This study found that, in a context where the demand for services by clients, in particular, Afghan newcomers, for both organizations has increased, these funding cuts had two major consequences: they ended the AAO settlement services; and they have resulted in the limitation of the settlement services provided by the AWO. Particularly, the funding cuts has been affecting the steady and successful settlement and integration of Afghan vulnerable refugee newcomers, despite their increased number of arrivals to Canada and high demand for services.

This research pointed out that the de-funding of the Afghan ethno-specific ISSAs' Refugee Assistance Program results into inaccessibility by Afghan refugees to essential services and exacerbates their vulnerability in Canada. Moreover, the insufficient funds for Language Skills Development Programs and Labour Market Participation Programs provided by these ISSAs impede social and economic settlement and integration of 
Afghan newcomers. As well, the lack of Support Services, and Information, Orientation, and Advocacy services, due to government funding cuts, further marginalizes Afghan newcomers by preventing their successful societal and cultural settlement and integration. The limitation of Community Connection and Youth Programs contributes to the inability of a new generation to negotiate between the two cultural identities, to successfully adapt to social, educational, and economic systems, deterring their positive contribution to the Canadian society. Thus, recognition theorists suggest that, in a multicultural society, recognition of newcomers' needs and distribution of services according to their needs, taken together, would allow for the right kind of justice, social cohesion, and a successful society.

All considered, this study fills the knowledge gap in this area by presenting the impacts of government funding cuts on services and service users of the ethno-specific ISSAs, in particular, the AAO and the AWO. These two case studies contribute to building understanding for and promoting recognition of provision of funding for services of the ethno-specific ISSAs. They also bring to the surface information on unsuccessful policies requiring adjustments. This study demonstrated the impact of funding cuts for Afghan ethno-specific ISSAs, paving the way for conducting research about other ethno-specific ISSAs impacted by the government funding cuts. This kind of study is important as it further advocates for ethno-specific ISSAs and newcomers, informs policy makers, raises awareness and recognition of newcomers' needs and their pre-arrival conditions, and leads to funding and provision of essential services, thereby facilitating effective settlement and integration of newcomers into Canada, in line with 
the principle of multiculturalism as well as its domestic and international human rights obligations.

\section{Policy Recommendations}

1. In contrast of mainstream ISSAs, the ethno-specific ISSAs are often small organizations with limited capacity and insufficient staff to compete for funding contribution agreements, provide professional reports, and meet the administrative burdens. However, literature and our findings assert that the ethno-specific ISSAs are more successful in settlement and integration of some newcomer populations than other ISSAs. Thus, the importance of multi-dimensional services of ethno-specific ISSAs and their positive impacts should be considered and recognized by government funders, contributing to provision of funding and services in order to enhance the newcomers' settlement and integration process.

2. The two ethno-specific Afghan ISSAs are the foremost organizations that effectively provide: culturally and linguistically competent services; language development, employment, counseling support services; and advocacy for marginalized Afghan newcomers. When funding cuts for the AAO and AWO were introduced and implemented by the government, it was overlooked that these organizations are providing essential services for a vulnerable refugee population with special needs, including language illiteracy, experience of war trauma and human rights violation, pre-migration life in exile with limited or no accessibility to public services. Both the literature and our findings assert that in the past three decades, these two Afghan ethno-specific organizations were more 
effective in serving, settlement and integration of Afghan refugees than the mainstream organizations. Policy makers should consider the pre-arrival condition of newcomer population each ethno-specific ISSAs serve before conducting funding cuts, in order to prevent newcomers' further vulnerability and inability to successfully settle and integrate into Canada.

3. The number of Afghan refugees settling in Canada are expected to increase, with a vast number of secondary Afghan newcomer migrants in Ontario; therefore, based on the past experience and lessons learned, for the effective settlement and integration process, the policy makers must take into account the expected increase of Afghan refugees and secondary migrants, and advocate for more funding and services provided by the ethno-specific Afghan organizations in Ontario.

4. The funding cuts and the government's goal to provide cost-efficient services has led ISSAs to recruit and appoint volunteers to provide services for newcomers instead of trained professionals. The provision of services for vulnerable refugee populations, in particular settlement and mental health counseling, require specialized staff to meet newcomers' needs. Policy makers should take into account that the provision of such services by unreliable and untrained volunteer staff may lead to an ineffective result. Hence, funding for ISSAs to hire specialized staff to deliver services for vulnerable refugee populations should be provided and is essential to meeting the true needs of these populations.

5. The government allocates the majority of funding for provision of direct settlement services. However, in this context the findings reveal that indirect 
settlement services are also effective, easily accessible, and convenient for Afghan newcomers across Canada. Therefore, this fact should be considered and each ISSA should be provided funding based on its best method of delivering settlement services to meet its newcomer clients' needs.

6. The government does not have a direct stream of funding for ISSAs to provide youth programs. This study's findings assert that the ethno-specific ISSAs meet the settlement needs of newcomer youth better than other institutions, including schools. Therefore, ISSAs should be considered for a direct stream of funding to provide essential services for youth. 


\section{References}

Afghan Women Catering Group. (2017). Brief History of Afghan Women's Catering Group. Retrieved from: http://www.awcg.org

Afghan Women's Organization. (2017). Vision and Mission. Retrieved from: http://afghanwomen.org/about-us/mission-and-values/

Ahmed, M. (2014). Violence against Afghan immigrant women in Canada: Cultural influences in help-seeking behaviours

Amir M. N. (2009). An analysis on the status quo of Afghan youth in the Ontario school system. Crossing the Finish Line. Afghan Association of Ontario, Canada

Annual Report. (2010). Afghan Association of Ontario. Toronto Annual Report. (2009). Afghan Women's Organization. Toronto Annual Report. (2010). Afghan Women's Organization. Toronto Annual Report. (2011). Afghan Women's Organization. Toronto Annual Report. (2012). Afghan Women's Organization. Toronto Annual Report. (2013). Afghan Women's Organization. Toronto Annual Report. (2014). Afghan Women's Organization. Toronto Annual Report. (2015). Afghan Women's Organization. Toronto Annual Report. (2016). Afghan Women's Organization. Toronto

Arfken, M. (2013). Social justice and the politics of recognition. The American Psychologist, 68(6), 475-476

Baskarada, S. (2014). Qualitative Case Study Guidelines. Defense Science and Technology Organization, (19), 40

Bedri Z. (2009). Immigrant and refugee youth issues - a perspective from York University students. High School Credential Assessment Program: Valuing Students from all Backgrounds. OCASI Serving Youth in Newcomer Communities (SYNC) 
Beiser, M. (2009). Resettling refugees and safeguarding their mental health: Lessons learned from the Canadian refugee resettlement project. Transcultural Psychiatry, 46(4), 539-583

Boyatzis, R. (1998). Transforming qualitative information: Thematic analysis and code development. Thousand Oaks, CA: Sage

Burhan, M. (2015). Tarekhcha Afghan hi moqem Canada. Toronto: Aryana Inc Translated. Burhan, M. (2015). History of Afghan Canadians. Toronto: Aryana Inc

Brown, R. (2009). TDSB Research Report. An Examination of TDSB Post-Secondary Patterns 17 Year old Student, 2007. Organization Development, Research and Information Services

Canadian Council for Refugees. (1998). Best Settlement Practices: Settlement Services for Refugees and Immigrants in Canada. Retrieved from: http://ccrweb.ca/sites/ccrweb.ca/files/staticfiles/bpfina1.htm\#ACKNOWLEDGEMENTS

Census Canada. (2011). Profile of Selected Social Characteristics: 2011 Census. Summary File 4 (SF 4) - Sample Data

Cheng, H. G., \& Phillips, M. R. (2014). Secondary analysis of existing data: Opportunities and implementation. Shanghai Archives of Psychiatry, 26(6), 371

Christie, M., Rowe, P., Perry, C., and Chamard, J. (2000). Implementation of Realism in Case Study Research Methodology. St. Mary's University

Collingridge, D. S., \& Gantt, E. E. (2008). The quality of qualitative research. American Journal of Medical Quality, 23(5), 389-395

Coulthard, G. S. (2007). Subjects of empire: Indigenous peoples and the 'politics of recognition' in Canada. Contemporary Political Theory, 6(4), 437-460

Creswell, J. W. (2014). Research design: Qualitative, quantitative, and mixed methods approaches (Fourth ed.) SAGE Publications

Department of Employment and Social Development Canada. (2016). Canadian Occupational Projection System. Government of Canada

Eakin, L. (2001). An Overview of the Funding of Canada's Voluntary Sector. The Voluntary Sector Initiative Working Group on Financing 
Faye, P. (2017). The politics of recognition, and the manufacturing of citizenship and identity in Senegal's decentralized charcoal market. Review of African Political Economy, 44(151), 66

Final Report. (2016, February). Afghan Association of Ontario

Final Report. (2016, June) Afghan Association of Ontario

Findlay, G. (2012). The house of Shafia. The Fifth Estate. CBC News

Flynn, E., Bauder, H., \& Ryerson Centre for Immigration and Settlement. (2013). The private sector, institutions of higher education, and immigrant settlement in Canada. Ryerson Centre for Immigration and Settlement

Funding Proposal. (2016). Development Plan for refugee settlement program. Afghan Association of Ontario

Funding Proposal. (2016). For Ministry of Citizenship, Immigration and International Trade. Afghan Women's Organization

Gana, N. (2009). Everyday Arabness: The Poethics of Arab Canadian Literature and Film. Michigan State University Press, (9), 2, pp. 21-44

Germain, Y. (2008). Modernizing the Settlement Program. Immigration, Refugee and Citizenship Canada

Ghafour, H. (2015). When Canada welcomed refugees - and paid their way. The Toronto Star

Ghufran, N. (2016). Afghan Refugees in Pakistan Current Situation and Future Scenario. Institute of Policy Studies, Islamabad, 3(2)

Goksel, G. U. (2014). The theory of recognition and the integration of immigrants

Hematyar, F. (2017). Development Plan for Refugee Settlement Program. Afghan Association of Ontario

Honneth, A. (1995). The struggle for recognition. Cambridge, MA: MIT Press

Hughes, G. (2008). The Soviet-Afghan War, 1978-1989: An overview. Defence Studies, $8(3), 326$

Hugman, R. (2004). Working with refugees: A guide for social workers. University of New South Wale

Ibrahimi, M. (2014). Zendage dar jawame dur az watan. Kabul: Pantone Kabul 
Translated. Ibrahimi, M. (2011). Life in Diaspora. Kabul: Kabul University

Immigration and Refugee Protection Act (IRPA) [Canada], SC 2001, c. 27. Justice Laws. Retrieved from: http://laws.justice.gc.ca/eng/acts/i-2.5/

Immigration, Refugee and Citizenship Canada. (2012). Grant and Contributions Manual

Immigration, Refugee and Citizenship Canada. (2014). Negotiation your contribution agreement with citizenship and immigration Canada: Settlement and Resettlement Programs. Retrieved from: http://www.amssa.org/wpcontent/uploads/2016/01/Recipient-Guidelines-January20141.pdf

Iser, M. (2013). Recognition. Stanford Encyclopedia of Philosophy. Retrieved from: https://plato.stanford.edu/entries/recognition/

Keung, N. (2010). Funding axed for Toronto immigrant agencies. Thestar

Keung, N. (2016). Food talent a hot commodity for immigration to Canada in 2015. Thestar

Khan, R. (2017). Legal Office. UNHCR, Toronto.

Khan, S.F. (2016). Afghan Refugees. Pakistan Today. Retrieved from: http://www.pakistantoday.com.pk/2016/02/01/comment/afghanrefugees/

Khwaja, K. (2016). A study of newcomer settlement services in Canada

Kohistani, V. (2012). Identifying cultural strengths of Afghan refugees as a source of their resilience

Kohlbacher, F. (2006). The use of qualitative content analysis in case study research. Forum : Qualitative Social Research, 7(1)

Kuschminder, K. and Dora, M. (2009). Migration in Afghanistan: History, Current Trends and Future Prospects. Maastricht Graduate School of Governance. Retrieved from: mgsog.merit.unu.edu/publications/external.../2009_Afghanistan_Countr y_Paper.pdf

Landesman, B. M. (1994). Multiculturalism and "the politics of recognition." Charles Taylor Amy Gutmann. Ethics, 104(2), 384-386 
Lim, A., Lo, L., Siemiatycki, M., Doucet, M. J., \& CERIS. (2005). Newcomer services in the greater Toronto area: An exploration of the range and funding sources of settlement services Joint Centre of Excellence for Research on Immigration and Settlement

Ludin, Q. (2008). Multi-Method Assessment of Newcomer Settlement Experiences in Waterloo

Malloy, T. (2014). Reconceiving recognition: Towards a cumulative politics of recognition. Journal of Political Philosophy, 22(4), 416-437

Marchand, K. (2014). Afghanistan Migration Profile. International Organization for Migration. Retrieved from: http://publications.iom.int/system/files/pdf/mp_afghanistan_0.pdf

Maxwell, J. (2009) Designing a qualitative study. In D. J. Rogg \& L. Bickman (Eds.) The Sage handbook of applied social research. Thousand Oaks: Sage

Mohsini, A. (2016). Afghan International Students Successfully Seek Asylum in Canada from the U.S. despite the Safe Third Country Agreement (unpublished research paper). Ryerson University. Toronto

Moswer, S. (2014). Afghan Professionals of Ontario. AAO TV

Mukhtar, M., Dean, J., Wilson, K., Ghassemi, E., \& Wilson, D. H. (2016). "But many of these problems are about funds...": The challenges immigrant settlement agencies (ISAs) encounter in a suburban setting in Ontario, Canada. Journal of International Migration and Integration, 17(2), 389408

Nazar, K. (2012). Opportunities And Challenges: Afghan Youth Learning English

Neuman, W. (2004). Basics of social research: Qualitative and quantitative approaches. Boston, MA: Pearson

Noh, S., \& Kaspar, V. (2003). Perceived discrimination and depression: Moderating effects of coping, acculturation, and ethnic support. American Journal of Public Health, 93(2), 232-238

Nordland, R. (2012, July 22). Top Afghans Tied to 90s Carnage, Researchers say. New York Times. Retrieved from: http://www.nytimes.com/2012/07/23/world/asia/key-afghans-tied-tomass-killings-in-90s-civil-war.html

Nusrat, A. (2015). Madodiate khadamat zarory baray taza-wareden Afghan dar Canada. Jameha Islami Afghan hai Canada 
Translated. Nusrat, A. (2015). The lack of essential services for Afghan newcomers in Canada. Afghan Canadian Islamic Community

OCASI. (2016). Telling our Stories from the Frontline: Adverse Institutional Impacts of Cuts to Immigrant Settlement Funding in Ontario

Ontario Government. (2017). Newcomer Settlement Program. Retrieved from: http://www.grants.gov.on.ca/GrantsPortal/en/OntarioGrants/GrantOppor tunities/OSAPQA005153

Oxfam International. (2009). The Cost of War: Afghan Experiences of Conflict, 19782009. Retrieved from:

https://www.oxfam.org/sites/www.oxfam.org/files/afghanistan-the-costof-war.pdf

Pagliaro, J., Mahoney, J. (2010). Funding cuts threaten immigrant agencies. The Globe and Mail

Pashtoonyar, A. (2011). Diaspora Communities and Canadian Foreign Policy: The Afghan Diaspora in Canada. Gordon Foundation \& the Mosaic Institute

Quirke, L. C. (2014). A study of the information practices of Afghan newcomer youth in the contexts of leisure and settlement

Report on “How Are We Doing?”.(2016). Afghan Women’s Organization

Report on Services. (2017). Afghan Association of Ontario

Report on Services. (2017). Afghan Women's Organization

Ricento, T., Cervatiuc, A., MacMillan, F., Masoodi, S. (2008). Insights into Funded ESL Program: Report on the LINC Program. Faculty of Education, University of Calgary

Richmond, T., Shields, J., CERIS, \& Metropolis Project. (2004). Third sector restructuring and the new contracting regime: The case of immigrant serving agencies in Ontario. Joint Centre of Excellence for Research on Immigration and Settlement

Rodrigues, L. (2017). Multiculturalism. Internet Encyclopedia of Philosophy. Retrieved from: http://www.iep.utm.edu/multicul/

Rossman, G. B., \& Rallis, S. F. (2012). Learning in the field: An introduction to qualitative research (Third ed.) SAGE Publications Inc 
Ruiz, H., Emery. M. (2001). Afghanistan's Refugee Crisis. Middle East Research and Information Project. Retrieved from:

http://www.merip.org/mero/mero092401

Sadiq, K. D., \& CERIS. (2004). The two-tier settlement system: A review of current newcomer settlement services in Canada CERIS: The Ontario Metropolis Centre

Shields, J., Drolet, J., \& Valenzuela, K. (2016). Immigrant Settlement and Integration Services and the Role of Nonprofit Providers: A Cross-national Perspective on Trends, Issues and Evidence Ryerson Centre for Immigration and Settlement

Sidiqi, F. (2012). Refugees' perceoved mental health post-migration to Canada: Afghans, Colombians and the Karen

Siemiatycki, M. (2015). Immigrant experiences in North America: Understanding settlement and integration. Canadian Scholars' Press

Simich, L., Beiser, M., \& Mawani, F. (2003). Social support and the significance of shared experience in refugee migration and resettlement: Special issue on the health of immigrant and refugee populations. Western Journal of Nursing Research, 25, 872-891

Song, S. (2016). Multiculturalism. The Stanford Encyclopedia of Philosophy. Retrieved from: https://plato.stanford.edu/cgi$\underline{\text { bin/encyclopedia/archinfo.cgi?entry=multiculturalism }}$

Statement of Operation. (2015). Afghan Women's Organization

Tania. (2014). Interpretation of Data: The Basics. Retrieved from: https://blog.udemy.com/interpretation-of-data/

Taylor. C. (1992). The Politics of Recognition. Retrieved from: http://elplandehiram.org/documentos/JoustingNYC/Politics_of_Recogni $\underline{\text { tion.pdf }}$

Taylor, C. (1994). The politics of recognition. In A. Gutmann (Ed.), Multiculturalism (pp. 25-73). Princeton, NJ: Princeton University Press

Tesol. (2017). Qualitative Research: Case Study Guidelines. Tesol International Association

The AWO Profile. (2016) Afghan Women's Organization 
The 1951 Convention Relating to the Status of Refugees. UN High Commissioner for Refugees (UNHCR). Retrieved from: http://www.unhcr.org/1951refugee-convention.html

Troster, H. (2016). Data Interpretation-The what, the why and the pitfalls of misinterpretation of data. Datapine

UNHCR. (2014). Zanai mahajer Afghan dar mohet dor az watan. Jadi Solh, Shar-e-Naw, Kabul, Afghanistan Translated. UNHCR. (2014). Afghan Refugee Women in Diaspora. Peace Avenue, Shar-e-Naw, Kabul Afghanistan

UNHCR. (2017). Global Trend: Forced Displacement in 2016. Retrieved from: http://www.unhcr.org/5943e8a34.pdf

UN Women Afghanistan. (2017). UN Women Asia and the Pacific. Retrieved from: http://asiapacific.unwomen.org/en/countries/afghanistan

Voices. (2012). Afghan Association of Ontario. Retrieved from: http://voicesvoix.ca/en/facts/profile/afghan-association-ontariohttp://voicesvoix.ca/en/facts/profile/afghan-association-ontario

Wali, M. (2014). Afghan youth in Toronto : Barriers to social inclusion

World Health Organization. (2015). Afghanistan: Mental Health. Retrieved from: http://www.emro.who.int/afg/programmes/mental-health.html

Yin, R. K. (2003). Case study research: Design and methods (3rd ed.) Sage Publications

Zainal, Z. (2007). Case Study as a Research Method. Faculty of Management and Human Resource Development University Teknologi Malaysia

Zhao, G. (2009). The Experience of Ethnocultural Communities in Supporting Newcomers in Edmonton: A Community Research. Prairie Centre for Excellence in the Research on Immigration and Integration (PCERII), Metropolis Project. 